University of Rhode Island

DigitalCommons@URI

Open Access Master's Theses

1987

\title{
The Breeding Ecology and Behavior of Northern Harriers in Coos County, New Hampshire
}

Patricia Serrentino

University of Rhode Island

Follow this and additional works at: https://digitalcommons.uri.edu/theses

\section{Recommended Citation}

Serrentino, Patricia, "The Breeding Ecology and Behavior of Northern Harriers in Coos County, New Hampshire" (1987). Open Access Master's Theses. Paper 970.

https://digitalcommons.uri.edu/theses/970

This Thesis is brought to you for free and open access by DigitalCommons@URI. It has been accepted for inclusion in Open Access Master's Theses by an authorized administrator of DigitalCommons@URI. For more information, please contact digitalcommons-group@uri.edu. 
THE BREEDING ECOLOGY AND BEHAVIOR OF NORTHERN HARRIERS IN COOS COUNTY, NEW HAMPSHIRE

BY

PATRICIA SERRENTINO

A THESIS SUBMITTED IN PARTIAL FULFILLMENT OF THE REQUIREMENTS FOR THE DEGREE OF MASTER OF SCIENCE IN ZOOLOGY

UNIVERSITY OF RHODE ISLAND

1987 


\section{MASTER OF SCIENCE THESIS}

OF

PATRICIA SERRENTINO

\section{APPROVED :}

Thesis committee

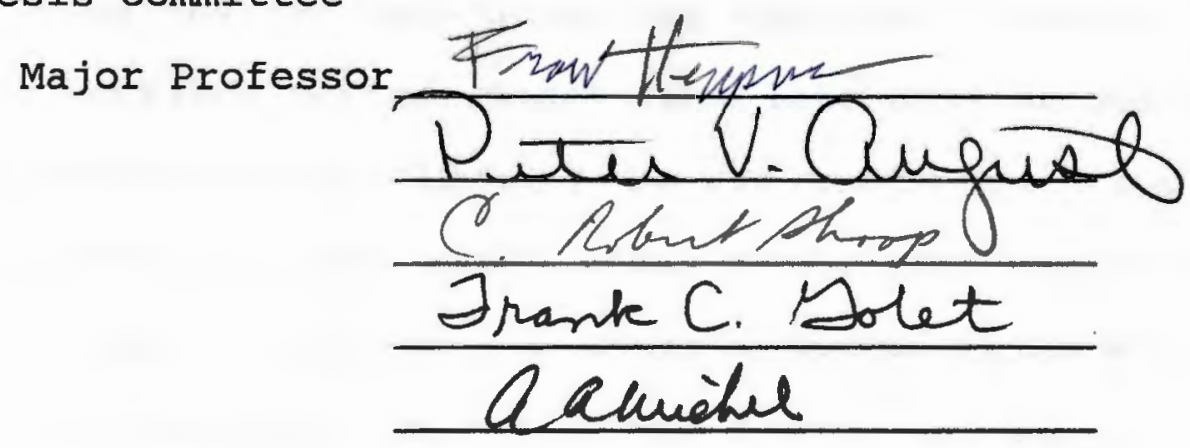

DEAN OF THE GRADUATE SCHOOL

UNIVERSITY OF RHODE ISLAND

1987 


\section{ABSTRACT}

Northern Harriers (Circus cyaneus) have experienced serious population declines throughout their breeding range in North America. In the northeastern United States, destruction and degradation of wetland habitats and the reforestation of open lands are the primary factors responsible for their decline. The breeding biology and hunting habitat selection and behavior of harriers in coos County, New Hampshire, were studied in 1984 and 1985 to provide baseline data on this population for management purposes.

In coos county, incubation and egg-laying begins in midMay, the nestling period ranges from late June to early August, and the young fledge from the end of July to midAugust. Nesting season range sizes of females varied from 1.42 to $4.0 \mathrm{~km}^{2}$. Data on the range sizes of males were incomplete. Harriers nested in old fields and shrub wetlands, in vegetation composed primarily of meadowsweet (Spiraea latifolia) and red-osier dogwood (Cornus stolonifera). The density of breeding birds in 1984 and 1985 ranged from 1 female per 5.0 to $6.7 \mathrm{~km}^{2}$. Mean fledgling production for the two-year period ranged from 2.6 to 2.7 young per successful nest.

Harriers were observed hunting in hayfields, edges, shrub habitats and forests. Males preferred hayfields over other habitats; females did not show a preference for any particular habitat. Hunting behaviors were observed which 
have not been reported in the literature, such as diving between trees, circling, and dipping flight. These behaviors were used by both males and females. Males spent more time using transect behavior than other flight types; females showed a preference for transect, circling and border following. Flight altitude was also determined for hunting harriers. Males exhibited a preference for lower flight altitudes; female appeared to spend slightly more time using higher flight altitudes.

Small mammal populations were sampled by live-trapping in several habitat types in 1985. Capture success was $1.5 \%$ for five fields. Small mammal abundance during 1985 appeared low in the habitats sampled. Pellets and prey remains were collected from four nests in 1985. On a qualitative basis, small mammals (subfamily Microtinae) were the most important prey item, with small- and medium-sized birds second.

A management plan for harriers in coos County would be difficult to implement because most land is privately owned. Landowner agreements may provide some protection to nesting birds. In other parts of New England and the Northeast, suitable breeding habitat should be surveyed for breeding harriers. Where possible, areas which support breeding populations should be protected from development. 


\section{ACKNOWLEDGEMENTS}

I extend special thanks to the members of my thesis committee; Drs. Peter August, Frank Golet and Robert Shoop, and my major professor, Dr. Frank Heppner, for their patience and guidance throughout my thesis research, and their interest in my project. I thank Dr. Keith Killingbeck for his advice on vegetation sampling techniques and his interest in harriers. Peg Barbour and Dolores Chadwick went beyond the call of duty to answer questions and obtain research supplies. Dr. Keith Bildstein, William DeRagon, Marilyn England, Dr. Frances Hamerstrom and Mark Manske provided advice on raptor biology and management techniques. Dr. Scott Melvin of the Massachusetts Natural Heritage Program, kindly granted me permission to use data collected on Northern Harrier biology and management in Massachusetts. Dr. William Glanz generously provided access to museum specimens at the University of Maine. I especially thank Dr. William Halteman of the University of Maine, for his statistical advice and guidance. The following people provided encouragement and a sense of humor when it was sorely needed: Maryanne Tilton, and Drs. John Anderson and Cynthia Mittelmeier.

I thank Carol Foss of the New Hampshire Audubon Society, for introducing me to Northern Harriers. Carol Foss and Flip Nevers also provided logistic and field help. I extend a special thanks to David and Barbara Killam of Columbia, New 
Hampshire, for sharing their knowledge of breeding harriers and for their generosity. The New Hampshire Department of Fish and Game, Paul Nugent, Bill and Lib Richardson and the Wade family graciously provided lodging during field work. I thank John Riff and Arlene Schmidt of the Agricultural Stabilization and Conservation Service in Lancaster, New Hampshire, for their patience and help with aerial photography and land use information. A special thanks to the people who assisted me during field work: members of the Endangered Species Program, James Galipault, Alex Haro, Joe Pacquin and Chris Serrentino.

Without the cooperation and assistance from the many land owners at the study area, my project would not have been possible. I especially wish to acknowledge the following people: John and Nancy Aimey, Fred and Sally Foss, Arthur Gould, Elaine and Hazen Haynes, the McAllisters and Raymond Placey. A special thanks to the shallow family, of Colebrook, New Hampshire, for their friendship and hospitality

The quality of my thesis and my graduate education at the University of Rhode Island were greatly enhanced by the knowledge, guidance and encouragement of the following people: Alex Haro, and Drs. John Anderson, Peter August, Frank Golet and Sally Levings. Their help with grantwriting, ecological field techniques and statistical and computer analyses is gratefully acknowledged. I thank Sarah 
Porter, my field assistant in 1985, for her patience with a difficult project, and her field ecology skills.

My research was supported in part by a Kathleen $\mathrm{S}$. Anderson Award from the Manomet Bird Observatory and a Grantin-Aid of Research from Sigma Xi in 1984 and 1985. I also received funding from the Audubon Society of New Hampshire, Frank M. Chapman Memorial Fund, The Nature Conservancy (Eastern Regional Office), and Vincent and Charlotte Serrentino. 


\section{PREFACE}

Population assessments of Northern Harriers have been conducted in several parts of North America since the early 1970's (Arbib 1973; Evans 1982; Tate 1986). As a result of these investigations, the harrier has been placed on 1 ists of special concern throughout its range. In New England, harrier populations are considered threatened in New Hampshire (Smith and Choate 1985), Vermont (Laughlin and Kibbe 1985), Connecticut (Dowhan and Craig 1976), Rhode Island (R. Enser, Rhode Island Department of Environmental Management, pers. comm.) and Massachusetts (R. Forster, Massachusetts Audubon Society, pers. comm.).

Current information on the breeding biology of harriers in New England is scarce. Historical data on this hawk's distribution and natural history can be found in Bendire (1892), Hoffman (1910), Forbush (1929) and Bent (1937). Recently, biologists from the Natural Heritage Program in Massachusetts have collected information on nest site selection and food habits of breeding harriers on Nantucket and Tuckernuck islands during their study of the endangered Short-eared Owl (Holt and Melvin 1986; Tate and Melvin 1987). Both of these raptors breed in the maritime heathland communities of off-shore islands.

My study was conducted with the cooperation and support of the Endangered Species Program, a joint project of the Audubon Society of New Hampshire (ASNH) and the New Hampshire 
Department of Fish and Game. I collected the following data on harriers to determine the status of the local population in Coos County, New Hampshire, and to design possible management plans for Northern Harriers: breeding biology, hunting habitat selection, hunting behavior, nest ecology, prey abundance and food habits.

Coos county was chosen as the study area because a population of approximately ten pairs had been monitored in the region since 1981. In addition, the human population density was low, thus minimizing problems of human disturbance during data collection. The locations of several breeding pairs were already known.

My thesis is comprised of three chapters: Chapter one focuses on harrier breeding biology, and includes breeding chronology, size of nesting season ranges, nest ecology, breeding density and dispersion, and fledgling production. Chapter Two concentrates on the relationship between hunting habitat selection, hunting behavior, small mammal abundance and prey selection. Chapter Three outlines the status of harriers in several regions of North America, with special emphasis on New Hampshire, and discusses possible management strategies for harriers in New England. 


\section{TABLE OF CONTENTS}

Abstract ii

Acknowledgments iv

Preface vii

Table of contents ix

List of Tables xii

List of Figures xiv

Chapter 1: The Breeding Biology of Northern Harriers in Coos County, New Hampshire 1

Introduction $\quad 2$

Study Area $\quad 3$

Methods $\quad 6$

Results 11

$\begin{array}{ll}\text { Discussion } & 25\end{array}$

$\begin{array}{ll}\text { Summary } & 32\end{array}$

Chapter 2: Hunting Behavior and Habitat Selection of Northern Harriers in Coos County, New Hampshire

Introduction $\quad 35$

$\begin{array}{ll}\text { Methods } & 37\end{array}$

$\begin{array}{ll}\text { Results } & 46\end{array}$

$\begin{array}{ll}\text { Discussion } & 72\end{array}$

$\begin{array}{lr}\text { Summary } & 84\end{array}$

Chapter 3: The Status of Northern Harriers in New England: Possible Management Strategies 86

$\begin{array}{ll}\text { Introduction } & 87\end{array}$

The Historic Distribution of Northern

Harriers in New England 
The Current Status of the Northern Harrier in North America, with Special Reference to New Engl and

An Evaluation of the Breeding Biology of the Northern Harrier in coos County

Possible Management Plans for Harriers in Coos County

Appendices

Appendix A: Natural History of Northern Harriers

Appendix B: Scientific and Common Names of Plant Species Observed at Nest Sites

Appendix C: Old Field Vegetation Analysis

Table Cl: Differences Among Cover Types (ANOVA) of Six old Fields in coos county

Table C2: Tukey's Test: Mean Cover Values

from the One-Way Anova Performed on the

Six Old Fields

Table C3: The Importance Values of Plant Species in Six old Fields

Appendix D: Scientific and Common Names of Plant Species Found in old Fields

Appendix E:

Table El: The Total Amount of Time That Harriers Were Observed; For Analysis of Habitat Selection

Table E2: The Total Amount of Time That Harriers Were Observed; For Analysis of Hunting Behavior

Table E3: The Total Amount of Time That Harriers Were Observed; For Analysis of Flight Altitude

Appendix F :

Table Fl: Raw Data for Habitat Selection of Individual Harriers

Table F2: Raw Data for Hunting Behavior Selection of Individual Harriers 
Table F3: Raw Data for Flight Altitude Selection of Individual Harriers

Table F4: Explanation of Abbreviations and Identification of Birds in Tables Fl to F3

Appendix G: Scientific and Common Names of

Mammal Species Trapped at the Study Area in 1985

Appendix H :

Table Hl: Prey Remains and Pellets Found at the Reed/Alex Nest Site, 1985

Table H2: Prey Remains and Pellets Found at the Mudget Mountain Nest Site, 1985

Table H3: Prey Remains and Pellets Found at the Forbes Hill Nest Site, 1985

Table H4: Prey Remains and Pellets Found at the Diamond Pond Nest Site, 1985 


\section{LIST OF TABLES}

Chapter 1

Table 1: Sites within the study area where nests, fledglings, and/or breeding behavior were observed in 1984

Table 2: Sites within the study area where nests, fledglings, and/or breeding behavior were observed in 1985

Table 3: Sizes of the nesting season ranges of five female Northern Harriers in Coos County

Table 4: Nest site characteristics of four Northern Harrier pairs, 1985

Table 5: Fledgling production of Northern Harriers in coos County, 1983 to 1987

Table 6: Summary of the density, fledgling production and mating system of North American and European studies of Circus cyaneus

Chapter 2

Table 1: Habitat types and subdivisions used by hunting harriers in coos county

Table 2: Height of vegetation in habitats used by hunting harriers in coos county

Table 3: Friedman pairwise comparison of male habitat preference based on duration

Table 4: Frequency of occurrence of the Diamond Pond harrier pair in the habitats surrounding the nest site

Table 5: 95\% confidence intervals on the fraction of occurrence of the Diamond Pond pair

Table 6: Frequency of occurrence of the Forbes Hill harrier pair in the habitats surrounding the nest site

Table 7: 95\% confidence intervals on the fraction of occurrence of the Forbes Hill pair 
Table 8: Habitat preference of the Diamond Pond and Forbes Hill pairs, based on time spent over the habitats surrounding the nest site

Table 9: Friedman pairwise comparison of female hunting behavior preference based on duration 58

Table 10: Friedman pairwise comparison of male hunting behavior preference based on duration

Table 11: Friedman pairwise comparison of female flight altitude preference based on duration

Table 12: Friedman pairwise comparison of male flight altitude preference based on duration

Table 13: Results of mammal trapping in six fields in Coos County, 1985: presented by field

Table 14: Results of mammal trapping in Coos County, 1985: presented by species

Table 15: Summary of pellets and prey remains found at four Northern Harrier nests, 1985

Chapter 3

Table 1: Fledgling production of Northern Harriers in Coos County, 1983 to 1987 


\section{LIST OF FIGURES}

Chapter 1

Figure 1: Study Area, Coos County, New Hampshire

Figure 2: Breeding Chronology of Northern Harriers in Coos County, From the Pooled Data of Six Pairs

Figure 3: The distribution of Northern Harrier nests within the study area, 1984 and 1985, including both successful and abandoned nests

Chapter 2

Figure 1: The flight altitude used by all harriers over each habitat type, based on duration 
CHAPTER ONE:

THE BREEDING BIOLOGY OF NORTHERN HARRIERS IN COOS COUNTY, NEW HAMPSHIRE 


\section{INTRODUCTION}

Recent studies of Northern Harrier breeding biology have been conducted in North and South Dakota (Duebbert and Lokemoen 1977), New Jersey (Dunne 1984), Missouri (Toland 1985), Massachusetts (Holt and Melvin 1986; Tate and Melvin 1987) and New York (England, in prep.), where harriers have experienced serious population declines. In New Hampshire, between 1969 and 1979, only seven breeding season records for harriers were reported, most from the northern parts of the state (Smith 1979). The Coos County study area contains the only known concentration of breeding harriers in New Hampshire and consists of approximately ten pairs (New Hampshire Endangered Species Program, unpubl. data). Ratcliffe (1977), Newton (1979) and Olendorff et al. (1982) stressed that the first phase of raptor management involves collecting data on population parameters such as density, reproductive success, nest site and hunting habitat selection, prey base and other factors. The objective of this chapter is to provide baseline data on the breeding chronology, nest ecology, size of nesting season ranges, breeding density and fledgling production of harriers in coos county. 


\section{STUDY AREA}

My study was conducted in coos County, New Hampshire, from May to August in 1984 and 1985. Coos County is in northern New Hampshire and has an area of 461,947 hectares. Approximately 95 percent of the county is forested and five percent is farmland, primarily dairy farms (U.S. Department of Commerce 1984; Frieswyk and Malley 1985). The major industries of coos county are timber production, dairy farming and tourism (J. Riff and A. Schmidt, Agricultural Stabilization and Conservation Service, Coos County, pers. comm., 1986 ).

The study area (Figure 1) is comprised of 32,340 hectares in the northwestern section of the county, and includes all or part of the towns of Pittsburg, Clarksville, Stewartstown, Colebrook and Columbia. Coos County contains three major landforms: rolling hills or plateaus, narrow river valleys, and steep mountains. The higher elevations average between 690 and 750 meters above sea level (Williams et al. 1943). The open habitats of the county are interspersed with extensive tracts of forests. These open habitats are concentrated within the study area and along the Connecticut River, which forms the border of New Hampshire and Vermont to the west.

The forests of coos County are located in the spruce/fir/northern hardwoods vegetation zone. The principal tree species of the spruce/fir association are red (Picea rubens), white ( $\underline{\text { P. glauca) }}$, and black spruce 


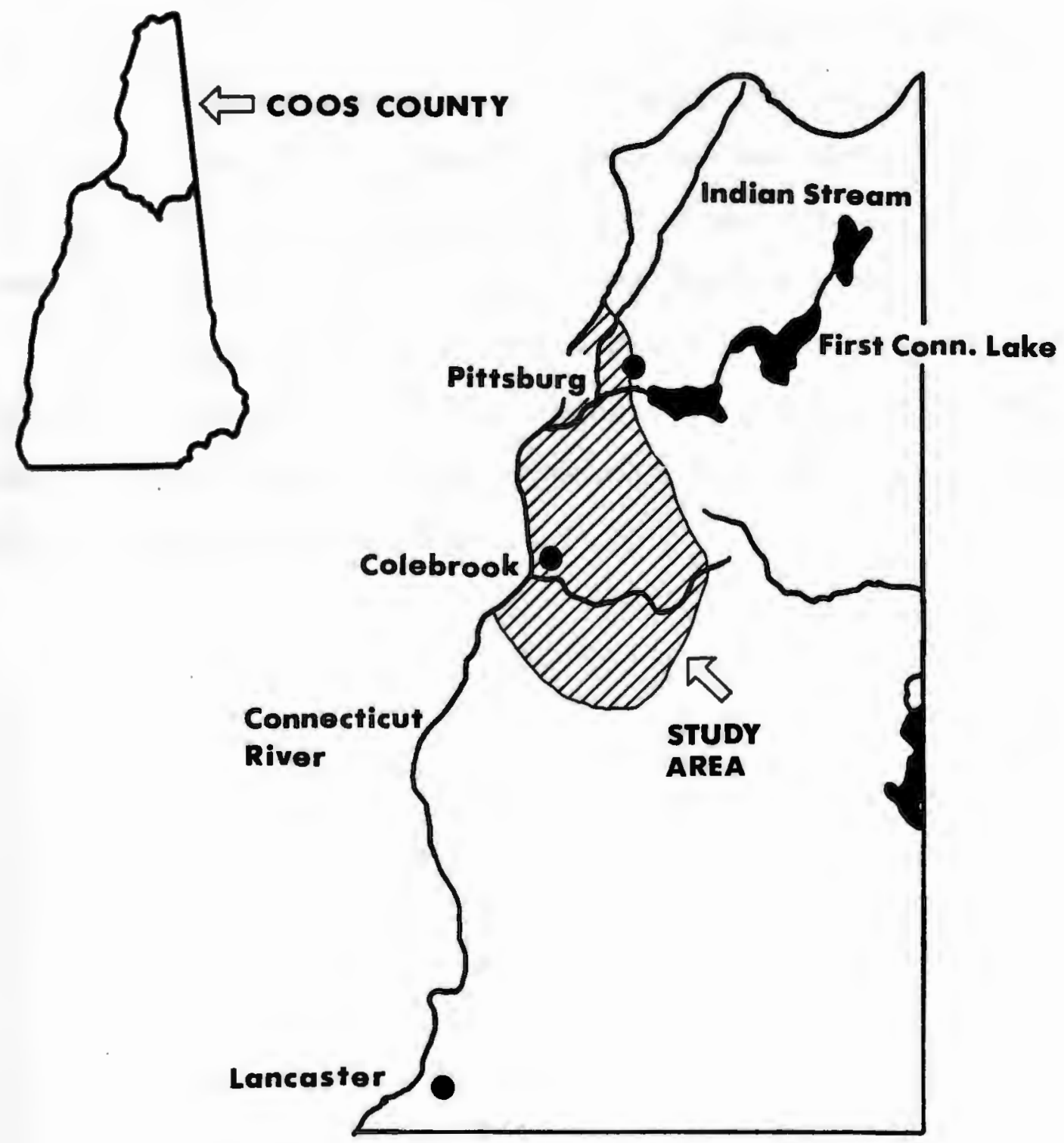

FIGURE 1: STUDY AREA, COOS COUNTY, NEW HAMPSHIRE 
(p. mariana), northern white cedar (Thuja occidentalis), balsam fir (Ábies balsamea), and American larch (Larix laricina). The northern hardwood association is composed of sugar ( $\underline{A c e r}$ saccharum) and red maple (A. rubrum), American beech (Fagus grandifolia), yellow (Betula lutea) and paper birch (B. papyrifera) and aspen (Populus spp.) (Westveld et al. 1956; Frieswyk and Malley 1985). Coos County has long cold winters and short cool summers. Because of the differences in elevation in the region, local weather conditions can vary greatly (Williams et al. 1943; Baldwin 1973). 


\section{METHODS}

\section{Breeding Chronology}

The length and onset of each breeding stage was determined using two methods: back-dating from fledging periods, and by observing the behaviors characteristic of each breeding stage. Both of these methods were used to prevent disturbance to nesting birds. Hamerstrom (1969) reported that females were prone to nest abandonment if disturbed during incubation. Because harriers are listed as a threatened species in New Hampshire, I was unable to visit nests until the young had fledged.

Incubation and hatching periods were estimated by observing the behavior of pairs at nests during May, June and July. During incubation, and continuing into approximately the middle of the nestling stage, the female rarely leaves the nest (Watson 1977). At this time the male supplies most of the food to the female and young (Hecht 1951; Schipper 1973; Picozzi 1978, 1980). The male provides the female with food by dropping prey to her in mid-air, either near or above the nest site. After the eggs hatch, the number of prey exchanges between the male and the female increases. As the young develop further, the female leaves the nest more frequently to hunt (Hecht 1951; Schipper 1973). Hatching dates can be estimated by noting an increase in the number of prey exchanges between the male and female, and an increase in the number of hunting trips by the female.

Newly-fledged harriers remain near their nests for 
several weeks (Hamerstrom 1969; Watson 1977). I noted the presence of juvenile harriers during nest observations from the end of July and into August. I defined fledge as occurring when the young birds were capable of short flights.

\section{Nesting Season Range Size}

I defined nesting season range as the area which encompassed all the activities of a pair of breeding harriers, including their hunting range and the area surrounding the nest site (Craighead and Craighead 1956, p. 247; Newton 1979, p. 40).

The sizes of harrier nesting season ranges were determined by observing nest sites from several observation points within a range. I chose points which afforded the widest view of the area surrounding the nest, allowing me to follow birds over fairly large distances. When possible, birds were followed by automobile or on foot when they left the nest to hunt. Because harriers were not marked, I did not include sightings of individuals unless I was positive of their identity (e.g., birds were followed as they left or returned to their nest).

I used the method outlined by craighead and craighead (1956) to determine range sizes: locations of hunting birds were plotted on aerial photographs with a scale of l inch to 3,330 feet. Lines were drawn connecting the outermost observation points for each individual. Ranges were digitized using ARC/INFO computer software (Environmental 
Systems Research Institute 1986), and areas calculated.

\section{Nest Ecology}

Nest sites were located by watching for food transfers between male and female harriers (Hamerstrom 1969) or by investigating areas of suitable habitat near a hunting or perched female. I did not attempt to locate nests until the young birds were able to make prolonged flights away from the nest site. Nests were located by walking transect lines through suspected nesting areas. Ground roosts and feeding sites were found at this time, and regurgitated pellets and prey remains were collected.

The following data were recorded at each nest: 1) general habitat type of nest site (old field or shrub wetland), 2) nest materials, 3) nest dimensions (outside diameter of the nest was measured at two points; depth of the nest was measured at the thickest area), 4) height off the ground (measured from bottom of nest to ground), 5) slope of nest site (measured with a transit to the nearest half degree), 6) elevation of nest site (estimated from topographic maps), and 7) the three most abundant plants (based on percent cover) within one meter of the nest.

\section{Breeding Density and Performance}

In 1984 and 1985, the distribution, density and fledgling production of breeding harriers in coos county were estimated using information collected by myself and volunteers from the Endangered Species Program, during 
searches of previous and new breeding sites. On Harrier Day, a one-day event sponsored by the Endangered Species Program, volunteers were stationed at various localities throughout the study area where evidence of breeding had been observed. Evidence of breeding included prey exchanges between adults and juveniles and/or the presence of juveniles over suitable nesting habitat. Harrier Day has been held every year since 1983, during mid-August. The abundance of breeding harriers is reported using ecological density (Eisenberg et al. 1979), which includes only those areas containing suitable habitat for the particular species involved. The study area contained large patches of forested area, unsuitable for nesting. I did not spend any time in these habitats looking for harriers. I determined the areas of those sites within the 32,340 hectares which had been searched during the breeding season or were covered by volunteers on Harrier Day. The boundaries of these areas were marked on aerial photographs with a scale of one inch equal to 2,000 feet $(1: 24,000)$. The total area covered was calculated using ARC/INFO computer software (Environmental systems Research Institute 1986). I used the total number of nests found at the study area in 1984 and 1985, including both abandoned and successful nests, to calculate density for each year. Fledgling production was determined by counting the number of fledglings observed at each successful nest. Because it was not possible to visit nest sites before fledge occurred, the above method was used to determine the 
number of fledglings produced per nest. Juvenile harriers remain near nest sites for approximately one to three weeks after fledging (Hamerstrom 1969; Watson 1977). 


\section{RESULTS}

Tables 1 and 2 contain a list of localities within the study area where either fledglings were observed and/or breeding behavior was seen during 1984 and 1985. The table also contains sites where breeding behavior was seen but nests apparently were abandoned for unknown reasons. Breeding behavior refers to all or one of the following, occurring over potential breeding habitat: 1) a prey exchange between the male and female, 2) the male and female flying together over suitable breeding habitat, and 3) defensive behavior by a bird toward avian or human intruders.

\section{Breeding Chronology}

The data collected from six nests were used to determine the breeding chronology of harriers within the study area, including: 1984, DP and FH; 1985, DP, FH, MM and RA (Figure 2). The observations from these nests contained the most complete information on breeding chronology. The length and time of occurrence of each breeding stage is presented as a range in Figure 2 because the data from the six nests were pooled and are based on estimates.

I used a range of 29 to 39 days to estimate the time period for both the egg-laying and incubation stages (Brown and Amadon 1968). Eggs are laid at two-day intervals (Hamerstrom 1969). At the study area, egg laying and incubation occurred from approximately mid-May, through 
TABLE 1: Sites within the study area where nests, fledglings and/or breeding behavior were observed in 1984. Sites are identified by a specific name and abbreviation.

Nest Location

Fate of Nest

Number of

Young Fledged

1) Washburn/Union School (WU)

2) Clarksville (CL)

Successful

3

Successful

2 School (BC)

4) Mudget Mountain (MM)

Successful

3

5) Killam/Columbia (KC)

Successful

1

6) Diamond Pond (DP)

Successful

4

Successful

3

( $\mathrm{FH}$ )

Successful

1

(RA)

Failed

0 (GB)

10) Hall Stream (HS)

Unknown

Presence of fledglings could not be verified 
TABLE 2: Sites within the study area where nests, fledglings and/or breeding behavior were observed in 1985. Sites are identified by a specific name and abbreviation.

Nest Location

Fate of Nest

Number of

Young Fledged
1) Washburn/Union School

2) Brown/Clevel and School

3) Mudget Mountain

4) Diamond Pond

5) Forbes Hill

6) Reed/Alex

7) Piper Hill ( $\mathrm{PH})$

8) Hall Stream
Failed

Successful

Successful*

Successful *

Successful *

Successful *

Successful

Failed
2

0

1

4

3

3

1

0

* Nests found; information on these nests is located in Table 4 . 


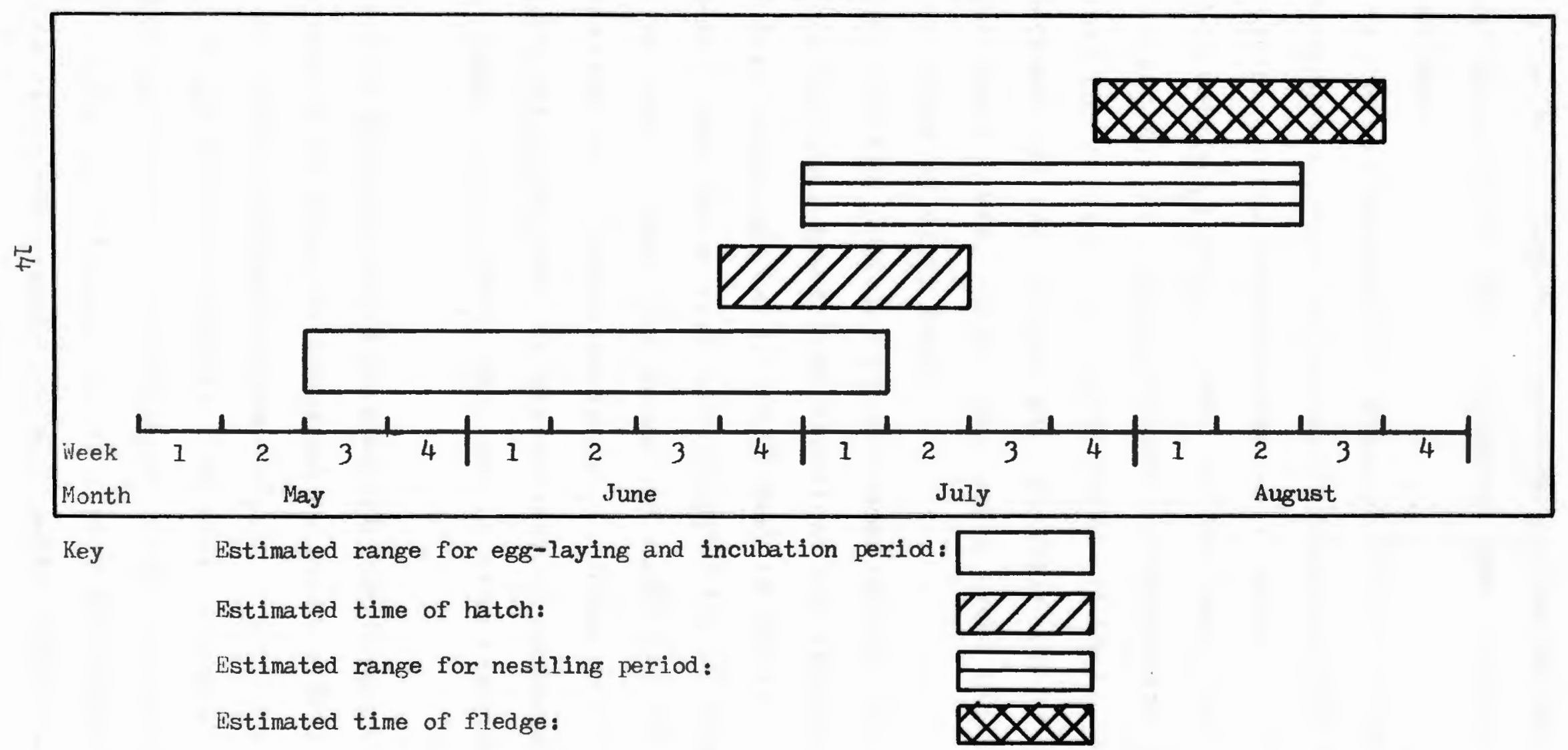

* 1984- Diamond Pond and Forbes Hil1; 1.985- Diamond Pond, Forbes Hill, Mudget Mountain and Reed/Alex. 
June, and into July. Because sightings of females were rare during the month of June, I assumed that incubation was in progress.

During the second and third week of July, the number of prey exchanges from males to females increased from one per observation period (approximately six hours) to five or six per observation period in 1984. At the same time the number of sightings of hunting females increased and I assumed that the young at the DP-84 and FH-84 nests had hatched between the end of June and the beginning of July. Hammond and Henry (1949) report that hatch takes place over a period of three to eight days.

During 1985 the behavior of adults at nest sites was not well documented. Exact nest locations for the MM-85 and FH-85 sites were not known until July 16 and 18 , respectively. Nest sites were not observed for as many hours in 1985 as in 1984. The number of sightings of hunting females still increased in July. These behavioral observations coincided with my estimations of incubation and hatch dates calculated by back-dating from fledging periods.

I assumed that the young birds had a nestling period of approximately 35 days, as reported by Urner (1925), Breckenridge (1935) and Hamerstrom (1969). I estimated that in 1984 and 1985 the eggs at five nests hatched between the end of June and early July, with the exception of FH-84. At FH-84, although the data from behavioral observations (i.e., the number of prey passes observed in 
mid-July) indicated a hatch date similar to the other nests, the birds did not fledge until mid-August. The eggs at the FH-84 nest may not have hatched until approximately July 15, and/or the nestling period may have been closer to 40 days rather than the 35 used to estimate nestling periods at other nests.

I determined that the young had fledged when the birds were observed perched in trees near their nest, and were able to fly short distances. At the DP-84 nest, the birds fledged between August 3 and 7 ; at FH-84, the young fledged between August 15 and 22. In 1985 the young from four nests (DP, FH, MM, and RA) fledged between July 29 and August 9 .

\section{Nesting Season Range Size}

I estimated the sizes of nesting season ranges for five females: $\mathrm{DP}$ and $\mathrm{FH}$ in 1984, and $\mathrm{DP}, \mathrm{FH}$ and $\mathrm{MM}$ in 1985 (Table 3). Range sizes for FH and DP in 1984 were 1.42 and $2.39 \mathrm{~km}^{2}$, respectively; for $\mathrm{FH}, \mathrm{MM}$ and $\mathrm{DP}$ in 1985, sizes ranged from 1.50 to $4.16 \mathrm{~km}^{2}$. The mean range size for the five females was $2.4 \mathrm{~km}^{2}$.

I did not include the range sizes of male harriers because the data collected were incomplete. I did not have as many observations of breeding males as females. Males were often sighted farther from the nest than females, where I could not be sure of their identity. 
TABLE 3: Sizes of the nesting season ranges of five female Northern Harriers in Coos County.

$\begin{array}{llll}\text { Breeding } & \text { Total Observation } & \text { No. Observation } & \text { Range } \\ \text { Female } & \text { Time (hours)* } & \text { Points** } & \text { Size } \\ & & & \left(\mathrm{km}^{2}\right)\end{array}$

\section{$\underline{1984}$}

Diamond

Pond

Forbes

80

67

1.42

$\mathrm{Hill}$

$\underline{1985}$

Diamond

63

43

4.16

Pond

Forbes

57

16

1.50

$\mathrm{Hill}$

Mudget

65

29

2.27

Mountain

* Total observation time refers to the number of hours that each nest was watched.

** Number of observation points refers to the number of sightings of each female used to construct range maps. 


\section{Nest Ecology}

Although no nests were found in 1984 , the general location of three (DP, FH, GB, Table l) was determined. During 1984 and 1985, a pair of harriers nested in the same old field at the Diamond Pond site (DP). The GB-84 and FH84 nest sites were located within shrub wetlands.

In 1985, four nests (Table 2) were located out of eight known breeding sites. No attempts were made to find the other four nests (WU, $\mathrm{BC}, \mathrm{PH}$, and $\mathrm{HS}$ ) due to time constraints and the lack of knowledge of exact nest location. Of the four nests located, two were in old fields and two in shrub wetlands (Table 4). The DP and RA nests were located in old fields on slopes; MM and FH were located in shrub wetlands on flatter terrain. All nests were found in dense cover; $M M, F H$ and $R A$ were located in extensive patches composed primarily of meadowsweet (Spiraea latifolia). The DP nest was placed in a patch of red-osier dogwood (Cornus stolonifera). Other abundant plants observed near nests were orchard grass (Dactylis glomerata), willow (Salix spp.), fireweed (Epilobium angustifolium), spotted Joe-pyeweed (Eupatorium maculatum), red raspberry (Rubus idaeus) and goldenrod (Solidago spp.).

Dead grasses were the primary constituents of nests; however, two contained small twigs (FH and RA). Pellets and prey remains were found at all nests, although the number of these items varied at each.

Nests were round in shape except for DP. It appeared 
TABLE 4: Nest Site Characteristics of Four Northern Harrier Pairs, 1985

\begin{tabular}{|c|c|c|c|c|c|c|}
\hline Pair & Habitat & $\begin{array}{l}\text { Nest } \\
\text { Composition }\end{array}$ & $\begin{array}{l}\text { Nest } \\
\text { Dimensions (cm) } \\
\text { a. depth } \\
\text { b. diameter } \\
\text { c. height of } \\
\text { ground }\end{array}$ & $\begin{array}{l}\text { Slope of } \\
\text { Nest Site }\end{array}$ & $\begin{array}{l}\text { Elevation } \\
\text { (meters } \\
\text { above sea } \\
\text { level) }\end{array}$ & $\begin{array}{l}\text { Three Most Abundant } \\
\text { Plants within One } \\
\text { Meter of Nest } \\
\text { (approximate height } \\
\text { of plant in meters) }\end{array}$ \\
\hline $\begin{array}{l}\text { Diamond } \\
\text { Pond } \\
\text { (DP) }\end{array}$ & $\begin{array}{l}\text { old } \\
\text { field }\end{array}$ & $\begin{array}{l}\text { dead } \\
\text { grasses }\end{array}$ & $\begin{array}{l}\text { a. } 8 \\
\text { b. } 38 \text { by } 65 \\
\text { c. } 12.5\end{array}$ & $\begin{array}{l}9 \text { degrees } \\
\text { down to } \\
\text { north; } 1 \\
\text { degree } \\
\text { down to } \\
\text { west }\end{array}$ & $\begin{array}{l}582 \\
\text { to } 588\end{array}$ & $\begin{array}{l}\text { a. Cornus } \\
\text { b. Dolonifera } \\
\text { Dactylis } \\
\text { glomerata } \\
\text { c. None }\end{array}$ \\
\hline $\begin{array}{l}\text { Reed/ } \\
\text { Alex } \\
\text { (RA) }\end{array}$ & $\begin{array}{l}\text { old } \\
\text { field }\end{array}$ & $\begin{array}{l}\text { dead } \\
\text { grasses } \\
\text { and twigs }\end{array}$ & $\begin{array}{l}\text { a. } 6.5 \\
\text { b. } 50 \text { by } 60 \\
\text { c. on ground }\end{array}$ & $\begin{array}{l}6 \text { degrees } \\
\text { down to } \\
\text { south; } 5.5 \\
\text { degrees } \\
\text { down to } \\
\text { east }\end{array}$ & 552 & $\begin{array}{l}\text { a. Spiraea } \\
\text { b. } \frac{\text { Rubus }}{\text { idaeus }}(1.6) \\
\text { c. Various }\end{array}$ \\
\hline $\begin{array}{l}\text { Forbes } \\
\text { Hill } \\
\text { (FH) }\end{array}$ & $\begin{array}{l}\text { shrub } \\
\text { wetland }\end{array}$ & $\begin{array}{l}\text { dead } \\
\text { grasses } \\
\text { and twigs }\end{array}$ & $\begin{array}{l}\text { a. } 8.5 \\
\text { b. } 50 \text { by } 60 \\
\text { c. } 4.2\end{array}$ & $\begin{array}{l}1.5 \text { degrees } \\
\text { down to } \\
\text { east; } 0 \\
\text { degrees } \\
\text { down to } \\
\text { south }\end{array}$ & 588 & $\begin{array}{l}\text { a. } \frac{\text { Spiraea }}{\text { Iatifolia }}(1.7) \\
\text { b. Epilobium } \\
\text { angustifolium }(1.4) \\
\text { c. Eupatorium } \\
\frac{\text { maculatum }}{\text { aculat }}\end{array}$ \\
\hline $\begin{array}{l}\text { Mudget } \\
\text { Mountain } \\
\text { (MM) }\end{array}$ & $\begin{array}{l}\text { shrub } \\
\text { wetland }\end{array}$ & $\begin{array}{l}\text { dead } \\
\text { grasses }\end{array}$ & $\begin{array}{l}\text { a. } 13 \\
\text { b. } 90 \text { by } 90 \\
\text { c. on ground }\end{array}$ & $\begin{array}{l}2.5 \text { degrees } \\
\text { down to } \\
\text { south; } 3 \\
\text { degrees } \\
\text { down to } \\
\text { east }\end{array}$ & $\begin{array}{l}684 \\
\text { to } 690\end{array}$ & $\begin{array}{l}\text { a. Spiraea } \\
\text { b. } \frac{\text { Cornus }}{\text { stolonifera }}(1.2) \\
\text { c. Salix spp. }(1.6)\end{array}$ \\
\hline
\end{tabular}


that the nest had become elliptical in shape because of the activity of the young. The outside diameter of nests ranged from 50 to $90 \mathrm{~cm}$ for round nests and 38 to $65 \mathrm{~cm}$ for the DP nest. Two nests (DP and $\mathrm{FH}$ ) were placed on the woody stems of shrubs, from 4.2 to $12.5 \mathrm{~cm}$ off the ground. MM and RA were located on the ground. The mean depth or thickness of four nests was $9.0 \mathrm{~cm}$. Although two nests were built in wet areas, standing water was not observed at the sites. The thickest nest (MM, $13 \mathrm{~cm}$ ) was found in a shrub wetland.

\section{Breeding Density and Performance}

Breeding harriers have been monitored by the

Endangered Species Program (ESP) since 1981; however, no data were available for that year. Table 5 contains the data collected from 1982 to 1987 on the fledgling production of harriers in coos county. In 1982, a local volunteer for the ESP located five juveniles at three sites. In 1983, the results from Harrier Day and from the ESP volunteer indicated that approximately 11 juveniles were fledged from six sites. In 1984 the number of young fledged was 18 from eight successful nests (DP, FH, WU, CL, $\mathrm{BC}, \mathrm{MM}, \mathrm{RA}$ and $\mathrm{KC}$ ) or 18 from nine nests (including the abandoned nest, GB; data from this study, volunteers from the Endangered Species Program, and Harrier Day). In 1985 the number was 14 from six successful nests (DP, FH, BC, $M M, R A$ and $P H$ ) or 14 from eight nests (including the abandoned nests, WS and HS). During 1986, using the 
TABLE 5: Fledgling production of Northern Harriers in Coos county, 1983 to 1987.

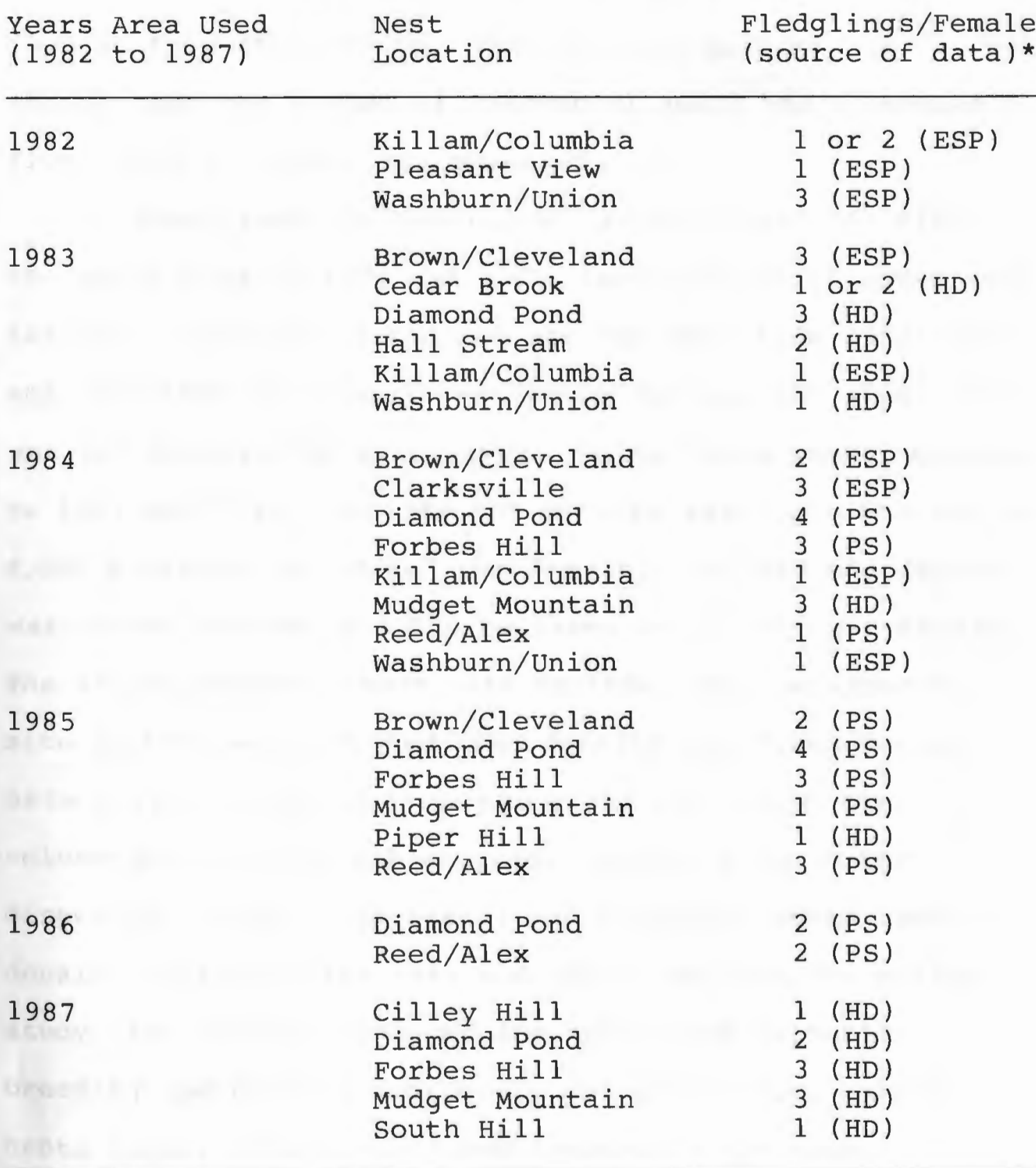

* PS: Present study

HD: Harrier Day

ESP: Volunteer, New Hampshire Endangered Species Program 
results of my four-day survey in mid-August, and results from Harrier Day and a volunteer from the ESP, only two successful nests were located. A total of four juveniles fledged from these nests. Results from Harrier Day in 1987 showed that the number of successful nests had increased to five, with 10 fledglings observed.

I determined the density of breeding harriers within the study area in 1984 and 1985, including sites where nest failures occurred. I did not use the data from 1982-1983 and 1986-1987 for density estimates because the study area was not surveyed as extensively during those years compared to 1984 and 1985. In 1984 the density was eight females in 4,005 hectares or $5.0 \mathrm{~km}^{2}$ per female. In 1985 the density was seven females in 4,576 hectares or $6.7 \mathrm{~km}^{2}$ per female. The Killam/Columbia nest site in 1984, and the Piper Hill site in 1985 were deleted from density estimates because data were not available on the areas covered by the volunteers from the ESP program. Figure 3 shows the dispersion of both successful and abandoned nests used in density estimates for 1984 and 1985. Because the entire study area was not surveyed for nests, and suitable breeding and hunting habitat is not continuous, harrier nests appear widely scattered throughout the area.

I determined the mean number of fledglings produced for successful nests and all nests (including apparent nest failures) in 1984 and 1985, when the most accurate counts of fledglings were available. In both years I used only those sites where I felt that all the young at one nest 


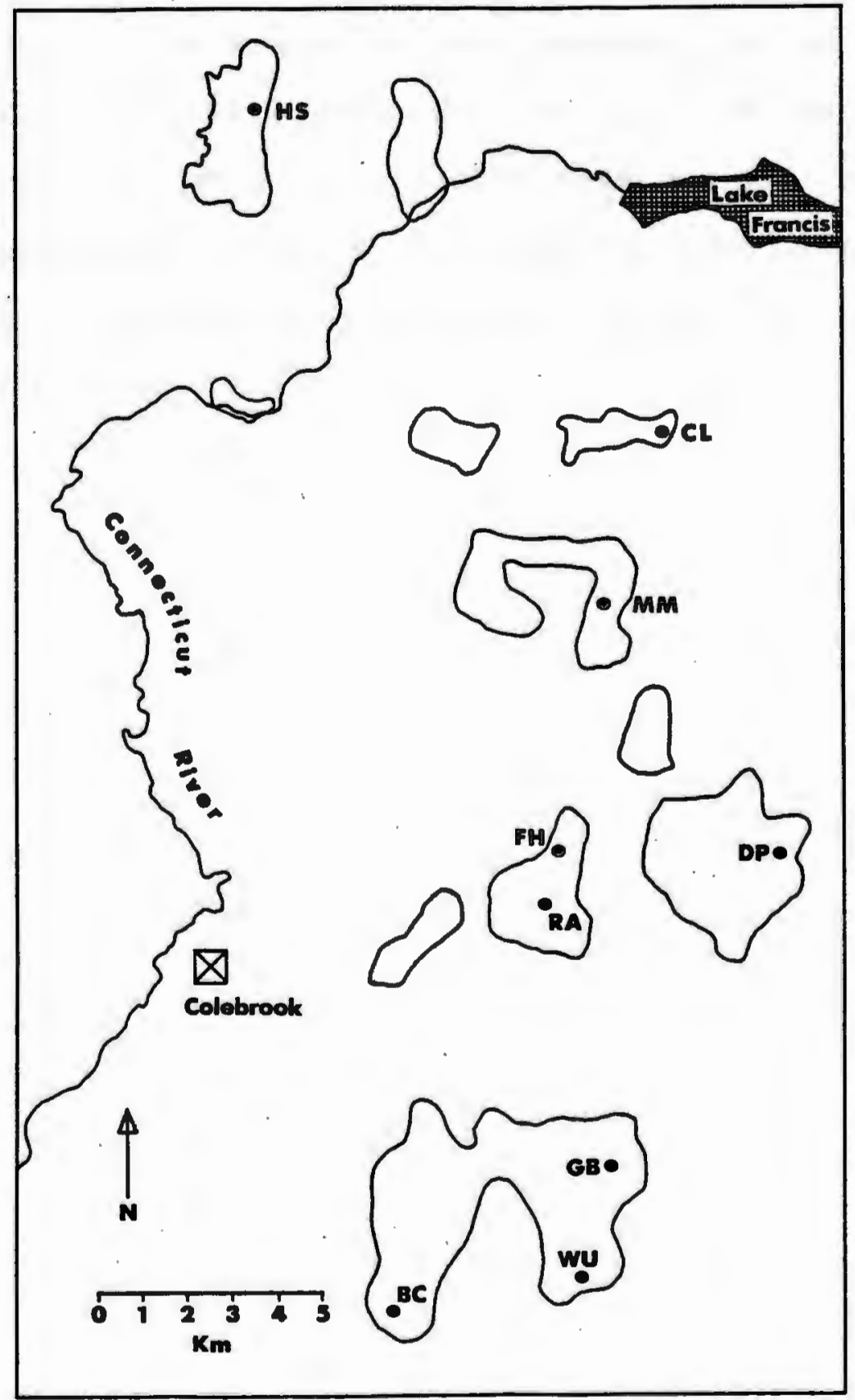

FIGURE 3: The distribution of Northern Harrier nests within the study area, 1984 and 1985; including both successful and abandoned nests. Outlined areas were included in estimates of density. Abbreviations correspond to those in Tables 1 and 2 . 
were found; during 1984, fledgling counts from Killam/Columbia and Reed/Alex were omitted, and in 1985 the results from Piper Hill were omitted. In 1984 the mean number of fledglings per successful nest was $2.7(\mathrm{~N}=6)$, and for all nests was $2.3(\mathrm{~N}=7)$. In 1985 the mean number of fledglings per successful nest was $2.6(\mathrm{~N}=5)$, and for all nests was $1.9(\mathrm{~N}=7)$. 


\section{DISCUSSION}

\section{Breeding Chronology}

From the data collected in 1984 and 1985, I estimated that egg laying occurred from mid-May to early June. Incubation took place from early June to the beginning of July. Hatch occurred from approximately the last week in June and into mid-July, and the young fledged from the end of July until mid-August.

These calculations are approximations because nests could not be visited until the young had fledged. In addition, differences between years and among nests would be expected because of weather conditions and variation among birds. Egg-laying may be delayed by cool weather in the spring (Watson 1977). Both Hammond and Henry (1949) and Watson (1977) reported a wide diversity in the length and onset of each breeding stage among individual harriers and between years.

The estimated dates of occurrence of each breeding event should prove useful for the determination of Harrier Day dates and for continued monitoring of harriers in coos County. Because most harriers fledged from the end of July until mid-August, breeding surveys conducted throughout this three week period instead of during one day would increase the accuracy of nest counts and fledgling production.

\section{Nesting Season Range Size}

The sizes of female nesting season ranges in Coos 
County were similar to those reported in previous studies. In Minnesota, the ranges of two harrier pairs were approximately $2.6 \mathrm{~km}^{2}$ (Breckenridge 1935), and in Michigan the ranges for 11 pairs varied from 1.0 to $5.6 \mathrm{~km}^{2}$ (Craighead and Craighead 1956). In the Netherlands, Schipper (1977) separated males from females when determining range sizes for the Hen Harrier, c. c. cyaneus. He reported that female range size varied from 0.1 to 5.4 $\mathrm{km}^{2}$; range sizes for males were larger.

Hecht (1951), Balfour and MacDonald (1970), Schipper (1977) and Picozzi (1978) stated that females hunted closer to the nest than males; the same phenomenon occurred in Coos County. Although males were observed hunting near nests, the number of observations for females was much higher.

The estimates of nesting season range size for female harriers are conservative because the terrain was hilly and it was easy to lose sight of hunting birds, and birds were not marked. I conclude that breeding females in coos County have minimum range sizes of 1.42 to $4.16 \mathrm{~km}^{2}$.

\section{Nest Ecology}

Northern Harriers nest in a wide variety of habitats and plant associations throughout North America: in stands of reeds and shrubs in salt and freshwater marshes (Hecht 1951; Dunne 1985), in raspberry bushes in shrubby uplands (Toland 1985) and in sphagnum bogs among shrubs and small trees (Bent 1937). Of the four nests discovered in 1985, 
all were located in dense clumps of red-osier dogwood or meadowsweet, in old fields or shrub wetlands. Harriers at the study area appeared to prefer plant associations similar to those reported by Hamerstrom and Kopeny (1981) in Wisconsin and Toland (1985) in Missouri, i.e., dense patches of shrubs and grasses. The nests were well-hidden from all sides except above, as described in other studies (Duebbert and Lokemoen 1977; Hamerstrom and Kopeny 1981; Toland 1985). Hamerstrom and Kopeny postulated that nests placed in thick vegetation may prevent nest predation because mammals rarely travel through these areas. Because harriers nest on the ground, concealment from predators may be one of the major factors responsible for the selection of dense cover at nest sites.

At the present time, suitable nesting habitat appears to be plentiful. However, only the general location of three nests was determined in 1984, and four were found in 1985. More data are needed to determine if harriers use additional habitats or plant associations. Other possible nesting habitats in the area include hayfields, dense stands of red raspberry bushes, and shrubby areas adjacent to rivers and streams.

\section{Breeding Density and Performance}

The density and fledgling production of breeding harriers is affected by several factors, such as the abundance of prey species (Hamerstrom 1969, 1979; Clark 1972; Simmons et al. 1986a.b.), the occurrence of polygyny 
(Hamerstrom et al. 1985; Simmons et al. 1986a.b.; Balfour and Cadbury 1975, 1979), the availability and quality of nesting habitat (Balfour and Cadbury 1975; Simmons and Smith 1985), and the age of the breeding bird (Hamerstrom et al. 1985; Simmons et al. 1986b.). The nesting densities of North American harriers in several studies were positively correlated with meadow vole (Microtus pennsylvanicus) abundance (Hamerstrom 1969, 1979; Clark 1972; Simmons et aㅣ. 1986a.b.).

The density of breeding harriers in coos County varied from 5.0 to $6.7 \mathrm{~km}^{2}$ per female (Table 6). The density of harriers in other studies in Europe and North America ranged from 1.2 to $13.3 \mathrm{~km}^{2}$ per female. In my study the mean number of young fledged per successful nest ranged from 2.6 to 2.7 , and for all nests was 1.9 to 2.3 (Table 6). The data from other studies ranged from 2.1 to 3.4 young per successful nest, and 0.72 to 2.3 for all nests. The causes of the variation between the breeding density and fledgling production of harriers in coos county compared to other studies would be elucidated by the following: 1) additional data on the both the prey base of breeding harriers and the abundance of their major prey species, 2) more intensive nesting surveys within the study area, including the addition of new areas which have not been censused, and 3) increased efforts to find all fledglings at each nest.

I conclude that the density and fledgling production 
TABLE 6: Summary of density, fledgling production and mating system of North American and European studies of Circus cyaneus

\begin{tabular}{lccc}
\hline Citation, & Density & Fledgling Production & Occurrence \\
Location, & (year: $\mathrm{km}^{2}$ & (Mean no. fledglings & of \\
Length of & per female) & per monogamous female) & Polygyny \\
study & & a. successful nests & \\
& & b. all nests
\end{tabular}

\begin{tabular}{|c|c|c|c|}
\hline $\begin{array}{l}\text { Craighead } \\
\text { and } \\
\text { Craighead } \\
\text { (1956) } \\
\text { Michigan } \\
2 \text { years }\end{array}$ & $\begin{array}{l}1942: 13.3 \\
1948: 10.0\end{array}$ & $\begin{array}{l}\text { a. not available } \\
\text { b. } 1942: 2.3 \text { ( } n=7) \\
1948: \text { all nests } \\
\text { failed before } \\
\text { hatch }(n=9)\end{array}$ & $\begin{array}{c}\text { Not } \\
\text { Available }\end{array}$ \\
\hline $\begin{array}{l}\text { Picozzi } \\
(1978) \\
\text { Scotland } \\
5 \text { years }\end{array}$ & $\begin{array}{rr}1973: & 10.9 \\
1974: & 8.0\end{array}$ & $\begin{array}{ll}\text { a. } & 3.1 \quad(n=19) \\
\text { b. } & 1.5 \quad(n=39) \\
& (\text { a } 11 \text { years })\end{array}$ & Infrequent \\
\hline $\begin{array}{l}\text { Balfour } \\
\text { and Cadbury } \\
\text { (1979) } \\
\text { Orkney Is., } \\
\text { Scotland } \\
7 \text { years }\end{array}$ & $\begin{array}{l}1971-73: 1.7 \\
1974: 1.3\end{array}$ & $\begin{array}{l}\text { a. } 2.8(n=23) \\
\text { b. } 2.3 \quad(n=28) \\
(\text { all years })\end{array}$ & Erequent \\
\hline $\begin{array}{l}\text { Dunne } \\
\text { (1984) } \\
\text { New Jersey } \\
2 \text { years }\end{array}$ & $\begin{array}{l}\text { Not } \\
\text { available }\end{array}$ & $\begin{array}{l}1979: \\
\text { a. } 2.3 \quad(n=7) \\
\text { b. } 0.89 \quad(n=18) \\
1983: \\
\text { a. } 2.07 \quad(n=15) \\
\text { b. } 0.72 \quad(n=43)\end{array}$ & $\begin{array}{c}\text { Not } \\
\text { Available }\end{array}$ \\
\hline $\begin{array}{l}\text { Hamerstrom } \\
\text { et al } \\
1985) \\
\text { Wisconsin } \\
25 \text { years }\end{array}$ & $\begin{array}{l}\text { Mean for all } \\
\text { years: } 12.7 \\
\text { During high } \\
\text { vole density: } \\
6.9 \text {, during } \\
\text { low vole } \\
\text { density: } 18.5\end{array}$ & $\begin{array}{l}\text { For all years: } \\
\text { a. } 3.1 \quad(n=252) \\
\text { b. } 2.3 \quad(n=252)\end{array}$ & $\begin{array}{l}\text { Averaged } \\
248 \text { for } \\
\text { all years }\end{array}$ \\
\hline
\end{tabular}


TABLE 6, continued.

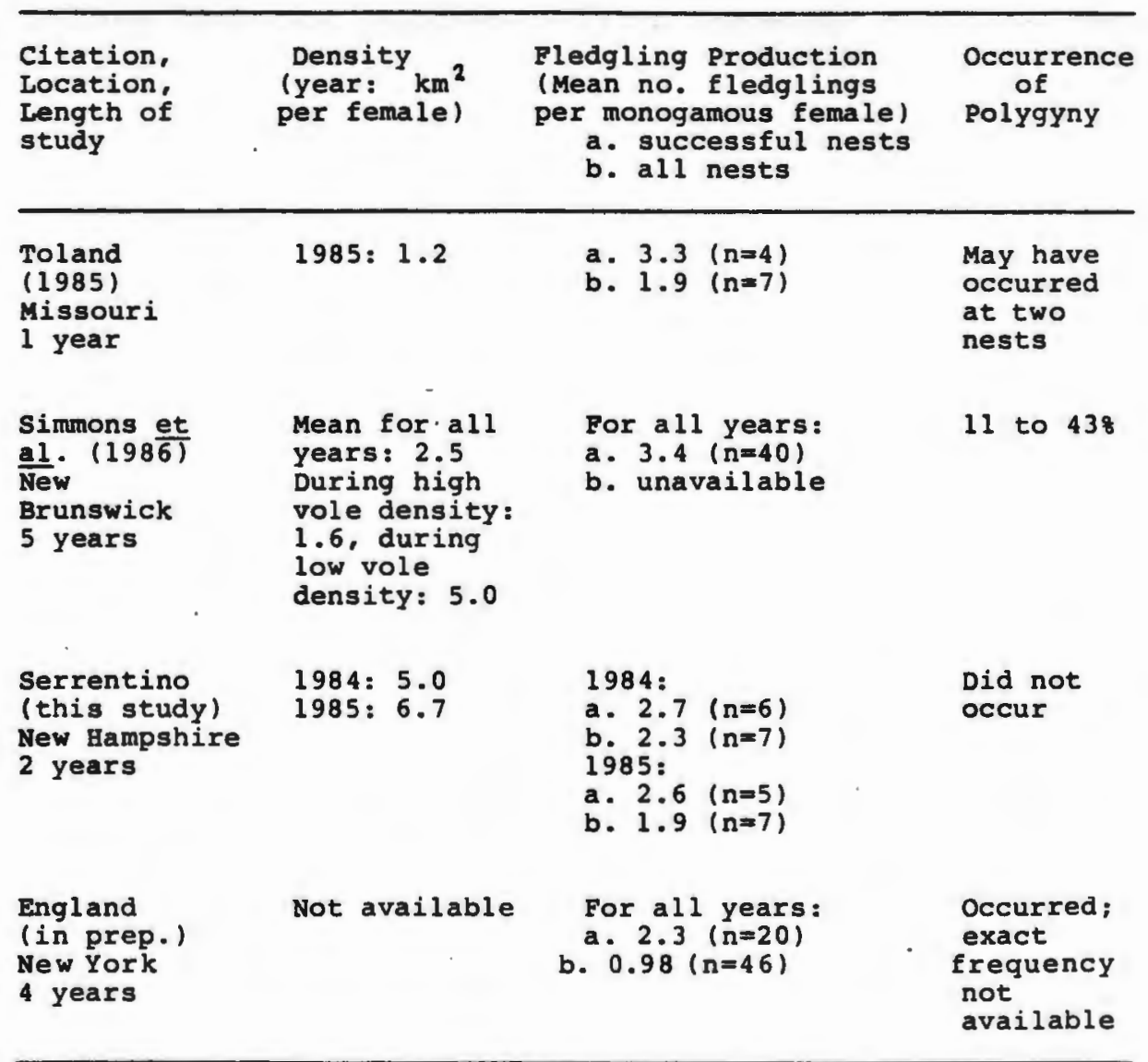


of harriers in coos county for 1984 and 1985 was probably not significantly lower than that reported for other areas where harriers were studied for long periods and populations had not suffered from recent, serious declines. 


\section{SUMMARY}

Northern Harriers nesting in Coos County, New Hampshire, began egg-laying and incubation in mid-May; incubation continued into approximately mid-July. Hatch occurred between the end of June and mid-July, and juveniles were observed flying near nest sites during the beginning of August. The length and time of occurrence of each breeding stage often varies annually because of the effects of weather and individual differences among birds.

Sizes of nesting season ranges of breeding females varied from 1.42 to $4.16 \mathrm{~km}^{2}$, but these should be considered minimum ranges only. More information is needed on the sizes of male ranges, and estimates of nesting season range size for both males and females would be improved by marking individual birds.

Nests were found in shrub wetlands and old fields. All were located in dense patches of shrubs, either meadowsweet or red-osier dogwood. Nests were composed of dead grasses and twigs.

The density of breeding harriers in coos county varied from 5.0 to $6.7 \mathrm{~km}^{2}$ per female, and fledgling production ranged from 2.6 to 2.7 per successful nest, and from 1.9 to 2.3 for all nests. These values were similiar to those reported for other populations. Because it was not possible to survey the entire study area extensively, some nests and fledglings were probably missed. More intensive censuses of the area for nesting pairs would increase the 
accuracy of density estimates and fledgling production of the coos county harrier population. 
CHAPTER T'WO:

HUNTING BEHAVIOR AND HABITAT SELECTION OF NORTHERN HARRIERS IN COOS COUNTY, NEW HAMSPHIRE 


\section{INTRODUCTION}

Hunting habitat selection in raptors is affected by many parameters, such as location of nests (Marquiss and Newton 1981; Kenward 1982; Simmons and Smith 1985), prey abundance and availability (Bednarz and Dinsmore 1981; Marquiss and Newton 1981; Janes 1985), vegetation structure (Craighead and Craighead 1956; Southern and Lowe 1968; Wakeley 1979; Bechard 1982), foraging behavior (Kenward 1982; Collopy and Bildstein 1987), the presence of competitors and predators (Bildstein 1978; Marquiss and Newton 1982; Janes 1984; Temeles 1986), topography (Janes 1985), and the sex of the bird (Koplin 1973; Bildstein 1978; Stinson et al. 1981; Marquiss and Newton 1981, 1982). Many studies have attempted to correlate habitat selection with several variables, such as vegetation cover, prey availability and abundance, morphology of the raptor species, and foraging behavior (Marquiss and Newton 1981; Bechard 1982; Kenward 1982; Janes 1985; Temeles 1986; Collopy and Bildstein 1987; and others).

Although habitat selection in wintering Circus cyaneus has been studied (Schipper et al. 1975; Bildstein 1978; Marquiss 1980; Temeles 1986; Collopy and Bildstein 1987), only Schipper $(1973,1977)$ and Martin (1987) studied the habitat selection of breeding harriers. The objectives of my study were to examine the effects of prey availability and abundance, vegetation cover and sex of the harrier on hunting habitat selection and behavior during the breeding 
season. Because harriers are assigned threatened status throughout New England, the data collected on hunting habitat selection can be used for planning management strategies for this raptor. 


\section{METHODS}

\section{Hunting Habitat Selection and Hunting Behavior}

Hunting habitat selection and behavior were observed near harrier nest sites. I also collected data on hunting birds whose breeding status was unknown. I used focal animal sampling (Altmann 1974) to record behaviors of harriers. Sampling began when I first sighted a bird and continued until it flew out of my field of view, captured prey, or perched for more than two minutes. Behavioral observations were tape recorded, and I noted the date, time, sex of the harrier, whether it was a known breeder or unknown bird, height of the bird above the ground (flight altitude), habitat type and behavior. Durations of observations were transcribed from the tape recorder using a stopwatch (Robinson and Holmes 1982; Beissinger 1983). At each observation point, at one-hour intervals, I recorded air temperature, wind speed and direction, relative humidity, cloud cover and precipitation.

Hunting habitats were classified on the basis of structural characteristics of the vegetation. Table 1 contains the habitat types observed at the study area. Habitats which were used by harriers only once were omitted. General habitat types were hayfields, forests, edge habitats, shrub wetlands, logged areas, pastures and old fields. Habitats with similiar vegetation structure (e.g., cut vs uncut hayfields) were identified as subdivisions within a particular general habitat type. 
TABLE 1: Habitat types and subdivisions used by hunting harriers in coos county.

Habitat Type

Subdivision

1. Hayfield

a. Uncut hayfield

b. Cut hayfield

c. old field (early successional stage*)

d. Wet meadow

2. Forest

a. Mixed forest

b. Conifer forest

c. Deciduous forest

3. Edge
a. Two hayfields
b. Forest and hayfield
c. Hayfield and old field
d. Hayfield and pasture
e. Hayfield and shrub wetland
f. Two pastures
g. Unknown edge

4. Old Field

(Late successional stage*)

5. Logged Area

None

6. Pasture

None

7. Shrub Wetland

None

* Note: Old fields were characterized as early or late successional stage based on both a quantitative and qualitative assessment of the amount of woody and grass cover present (see Appendix C for results of analyses). 
Forests, hayfields and edge habitats were composed of several subdivisions.

During 1984 I determined the habitat selection of two pairs of harriers (Diamond Pond and Forbes Hill) by comparing the number of observations of each pair around their nest site with the proportion of each habitat type available. The habitats included in the analysis surrounded each nest, corresponding roughly to their nesting season ranges, and could be seen from several observation points from which I watched the breeding pair. Habitat types were determined and boundaries delineated using a lens stereoscope to view black and white aerial photographs in three dimensions. This method was used to increase the accuracy of habitat determination when it was impossible to survey an entire area on foot. These photographs were taken in 1982; their scale was one inch equal to 2000 feet $(1: 24,000)$. The area encompassed by each habitat type was calculated using the ARC/INFO digitizing system (Environmental Systems Research Institute $1986)$.

The flight altitude of hunting harriers was estimated by sight. Because of the irregular topography (many hills and valleys) and the variable heights of different vegetation types, I classified flight altitude into the following ranges: 1) low altitude: the bird flying $1 \mathrm{~m}$ or less above the ground; 2) medium altitude: the bird flying from 1 to $9 \mathrm{~m}$ above the ground; 3) tree-top altitude: the 
bird flying from 9 to $25 \mathrm{~m}$ above the ground, depending on the tree species; 4) above the trees: the bird flying above the tallest trees in the habitat (approximately $12 \mathrm{~m}$ and above).

Vegetation heights were determined to provide estimates of the flight altitude of hunting harriers. Table 2 contains the mean heights of vegetation in each habitat type and subdivision. Heights were obtained by measuring five samples from the tallest vegetation in each habitat with a meter stick or by clinometric estimation. For habitats with subdivisions, such as forest, edges and hayfields, each subdivision was sampled. Forests contained the tallest trees, as expected, and tree heights ranged from 18.4 to $22.4 \mathrm{~m}$. Mature trees and saplings also occurred between the edges of two habitats, and within logged areas, late successional old fields and pastures. Vegetation in these habitats ranged from $5.7 \mathrm{~m}$ for trees in shrub wetlands, to $18.2 \mathrm{~m}$ in edge habitats. The height of the shrub layer in old fields and shrub wetlands ranged from 1 to $2 \mathrm{~m}$. A thick shrub layer was the dominant feature of the vegetation structure of these habitats. Vegetation height was measured in hayfields during June and August. Five measurements were taken during each month. In the early summer, the mean height of the vegetation in hayfields was $0.49 \mathrm{~m} \mathrm{high,} \mathrm{and} \mathrm{during} \mathrm{August} \mathrm{was} 0.99 \mathrm{~m}$ high.

I observed harriers for three weeks in 1984 to become familiar with hunting behaviors. After this time, 
TABLE 2: Height of vegetation in habitats used by hunting harriers in Coos county.

Habitat Type and Subdivsion

1. Hayfield

2. Forest

1. Mixed Forest

2. Conifer Forest

3. Deciduous Forest
Mean Height (in meters) and Standard Deviation

$$
\begin{aligned}
& 0.49 \pm 0.23 \text { (June) } \\
& 0.99 \pm 0.12 \text { (August) }
\end{aligned}
$$

3. Edge

1. The woody border between $15.6 \pm 5.0$ two hayfields $20.7+3.4$ $18.4 \mp 5.0$ $22.4 \pm 4.0$

2. The border between hayfield and forest

$18.2 \pm 4.2$

4. Old Field

(late successional stage)

$12.3 \pm 3.2$ (trees)

$1.6 \pm 0.17$ (shrubs)

5. Logged Area

$16.2 \pm 7.8$ (trees)

6. Pasture

$7.7 \pm 3.0$ (trees)

7. Shrub wetland

$5.7 \pm 3.3$ (trees)
$1.5 \pm 0.03$ (shrubs) 
observations were recorded on tape and used for analysis. I followed Craighead and Craighead (1956), Schipper et al. (1975), Schipper (1977), and Bildstein (1978) in distinguishing hunting from non-hunting behavior.

Eight different hunting behaviors were recognized in this study; transect, quartering, border following, hover flying, ground hunting, circling, diving between trees and dipping flight. Transect, quartering, border following and hover flying were observed in the harriers studied by Bildstein (1978, p. 179). Transect flight was defined as straight line flight with less than five sharp (> 30 degree) turns per minute. Quartering flight was defined as flying back and forth over short distances with more than five sharp turns per minute. Border following flight occurred parallel to and within five meters of the border between two different habitat types. Hover flying consisted of hovering over one spot, followed by short periods of flapping or gliding.

My definition of ground hunting in harriers was modified from Craighead and Craighead (1956, p. 53). During a hunting bout, harriers landed on the ground for periods ranging from several seconds to several minutes. I assumed that an individual landing on the ground without capturing prey during a hunting bout, and remaining there for more than ten seconds, was ground hunting (scanning the ground for prey).

Circling, diving between trees and dipping flight were additional hunting behaviors I observed. Circling flight 
was defined as flight over a small area in tight circles. Diving between trees was defined as flying between trees, at varying heights from the ground. Dives toward the trees or the ground frequently occurred. Dipping flight was similar to transect flight in that the bird flew in a fairly straight line; however, flight altitude varied.

For data analyses I interpreted harrier hunting behaviors conservatively, to avoid including those that were associated with breeding or were merely movements of birds to other areas. I omitted the following behaviors: 1) circling of males or females over nest sites, 2) soaring flight, and 3) observations of harriers carrying prey.

\section{Mammal Abundance}

To determine the abundance of small mammals at the study area, rodents were live-trapped in six fields from June 30 to August 22, 1985. The fields consisted of two hayfields and four old fields. Hay fields were mowed by landowners approximately every two years. Old fields were categorized as early or late successional stages; two were early successional stage and two were late successional stage (see Appendix $\mathrm{C}$ for a discussion of the difference between early and late successional stages).

Each field was trapped for four consecutive nights using approximately 60 Sherman live-traps per night. Traps were baited with a mixture of peanut butter and rolled oats, and were placed in three parallel lines running from the edge of the field to the middle. At Moose field (a 
hayfield), traps were placed along three edges because of the wishes of the property owner. At all fields, trap lines were placed $15 \mathrm{~m}$ apart, with $4.5 \mathrm{~m}$ separating each trap. Traps were set between 1700 and $1930 \mathrm{~h}$ and were checked between 0500 and $0600 \mathrm{~h}$. At each trap I recorded the species (Burt and Grossenheider 1976) and age (adult or juvenile) of the individual. Individuals from the genus Peromyscus were not identified to species. Captured animals were marked by cutting the fur between their ears. I also recorded any traps which were closed but did not contain animals, and those that had bait removed.

Trapping results presented relative to intensity are based on the number of captures per functional trap night (total trap nights minus the number of sprung traps). I chose this conservative measure because I did not know if a sprung trap became unavailable to small mammals early or late during a trap night.

\section{Pellet Analysis}

During 1985, pellets and prey remains were collected at four nests (Diamond Pond, Mudget Mountain, Forbes Hill, Reed/Alex), and from perches, ground roosts and feeding sites. Pellets contain the indigestible remains (fur, feathers, bone, claws, teeth, etc.) of prey eaten by raptors. Before dissection, pellets were air-dried and prey remains were dried in an oven when neccessary. Each pellet was then dry-dissected and the contents recorded. In addition to animal remains, the presence of insects and 
vegetation was also noted. Dissected pellets and prey remains were examined under a dissecting microscope and compared with museum specimens from the University of Rhode Island and University of Maine mammal and bird collections. Mammal skulls were identified with the aid of keys (Glass 1951; Hall 1981) and museum specimens.

Pellets were analyzed according to the method recommended by Errington (1932). Fragmented pellets from one area, specific nest or ground site were dissected together. The frequency of each item (animal) in the pellets was recorded (Balfour and MacDonald 1970). Quantitative data were recorded only if a skull or part of the skull was found intact. Remains were identified to species whenever possible. 


\section{RESULTS \\ Hunting Habitat Selection and Hunting Behavior}

\section{Sample Sizes, Number of Observation Hours}

During 1984, I observed the hunting behavior and habitat selection of three harrier pairs from early June until the end of August: Diamond Pond (DP), Forbes Hill (FH), and Gould/Bungy (GB). During the end of June an apparent nest failure occurred at the GB site, because neither the male or female was observed at the nest site after this time. As a result, the data collected during 1984 are primarily from two breeding pairs, DP and FH. other habitats were also surveyed for hunting harriers, and were included in the data analysis under unknown birds (e.g., birds whose breeding status was unknown). During 1985 a full-time research assistant collected data on the breeding behavior of adults at nests, permitting me to monitor the hunting behavior and habitat selection of additional pairs. Five pairs were observed; DP, FH, Mudget Mountain (MM), Hall Stream (HS), Washburn/Union School (WS), and Reed/Alex (RA). Apparent nest failures occurred at HS and WS. Hunting data collected on breeding birds were primarily from DP, FH, MM and RA. Hunting data collected on birds in 1985 were not as complete as in 1984.

The amount of time spent observing the hunting behavior and habitat selection of breeding birds in 1984 was 127 hours; an additional 33 hours were spent watching 
unknown birds (includes observations taken from mid-June until the end of August, when data on duration was recorded with the tape recorder). During 1985, the amount of time spent collecting data on the hunting behavior and habitat selection of breeding birds was 172 hours; 78 additional hours were spent watching unknown birds (includes observations taken from the end of May until the end of August).

For data analysis, breeders and unknown birds and data from 1984 and 1985 were pooled because of the low number of observations at nests in 1985, and the low number of observations of unknown birds in 1984. Most of the data collected on hunting habitat selection and behavior of females in 1984 and 1985 were from known breeders (86\% to 88\%); therefore, females were evaluated as breeding birds. Males, however, were difficult to assess with respect to habitat selection and hunting behavior because they were not observed hunting close to nests as frequently as females. I was only able to collect data on hunting males by observing outside the immediate vicinity of nests, where I could not be sure of their breeding status. I also did not have any knowledge about the number of non-breeding males in the population, because birds were not marked. The data collected on males for both years is composed of approximately 50\% unknown birds and $50 \%$ breeders. For data analysis males were evaluated as breeders because: 1) I was certain that at least $50 \%$ of the observations were composed 
of breeding males, and 2) approximately half of the unknown birds were probably breeders, because of the proximity of most individuals to known nests.

Tables 1, 2 and 3 in Appendix E summarize the data used to analyze habitat selection by year, breeding status, sex, number of birds and total duration. These tables indicate sample sizes for comparison of females vs males, breeders vs unknown birds, 1984 data vs 1985 data, the total number of birds in each category, and the total duration (in seconds) of observations for each category.

\section{Habitat Selection}

To determine whether males or females preferred one habitat over another, I performed a Friedman's test (Conover 1980) on duration (in seconds) spent over each habitat type for each sex. The Friedman test is a nonparametric test which analyzes several pairs of related samples (e.g., amount of time each sex spent over each habitat). For females, the following habitat categories were used; hayfields, forest, edges, shrub and pasture. The shrub category was composed of pooled observations from logged areas, shrub wetlands and late successional old fields because there were not enough observations over of each these habitats separately. These habitats had similar vegetative structure; most had a distinctive shrub layer, open space in the form of grasses and forbs, and scattered trees. Females did not exhibit a preference for any particular habitat type (Friedman's test, p > .05). 
For males, pastures were not analyzed because there were not enough observations to make a comparison. The following habitats were analyzed: hayfields, forests, edges and shrub habitats. Unlike females, there was a significant difference between the length of time that males spent over each habitat (Friedman's test, $p<.05$ ). Table 3 contains the results of the pairwise comparisons for male habitat use. Significantly more time was spent over hayfields than forest, edge and shrub habitats (Friedman's pairwise test, $p<.05)$.

To determine if males and females selected habitats differently, a Wilcoxon two-sample test was performed using duration data from hayfield, forest, edge and shrub habitats. Use of pastures was deleted because of the lack of data for males. There was no difference between males and females with respect to the relative amount of time each sex spent over the four habitats (wilcoxon test, $p$ ) .05). The amount of time birds spent over each habitat is presented in Appendix Fl.

I used the technique presented by Neu et al. (1974) to determine which habitats surrounding harrier nests were being used by breeding pairs significantly more or less than expected, based on the availability of those habitats. The number of observations of a pair over each habitat was used instead of duration (time spent over each habitat) because a test statistic was not available to determine habitat preference using duration. The results of the habitat selection of the Diamond Pond (DP-84) and Forbes 
TABLE 3: Friedman pairwise comparison of male habitat preference based on duration.

\begin{tabular}{lccccc}
\hline & & $\begin{array}{c}\text { HAY } \\
(67.5)\end{array}$ & $\begin{array}{c}\text { FOREST } \\
(44.5)\end{array}$ & $\begin{array}{c}\text { EDGE } \\
(48.0)\end{array}$ & $\begin{array}{l}\text { SHRUB } \\
(40.0)\end{array}$ \\
\hline HAY & $(67.5)$ & 0.0 & $23.0 *$ & $19.5 *$ & $27.5 *$ \\
FOREST & $(44.4)$ & - & 0.0 & 3.5 & 4.5 \\
EDGE & $(48.0)$ & - & - & 0.0 & 8.0 \\
SHRUB & $(40.0)$ & - & - & - & 0.0 \\
\hline
\end{tabular}

Rank sums (of duration) in parentheses; table values denote differences between paired rank sums.

* Denotes significant differences between the rank sums at the $\mathrm{p}<.05$ level. 
Hill (FH-84) pairs were used for this analysis because the most complete data were collected from these pairs. Because males and females of each pair did not exhibit significant differences in their use of the habitats around nests when compared with each other (Chi square test, p< $.05)$, the data from both sexes were analyzed together.

I found highly significant differences between the observed number of sightings of birds in each habitat and the expected number, based on habitat availability, for both pairs (Chi square test, $\mathrm{p}<.001$ ). To determine which habitat categories were used more or less than expected, I calculated the $95 \%$ confidence interval around the proportion of the total number of observations made in each habitat. If the proportion of total habitat available fell within the 95\% interval, there was no significant difference between habitat use and habitat availability. If the amount of habitat did not fall within the $95 \%$ interval, there was significant attraction to, or avoidance of, the habitat. Tables 4 and 6 contain the data used to calculate the confidence intervals. The confidence intervals for the use of each habitat type are presented in Tables 5 and 7. For the DP pair (Table 5), no significant difference in the use of old fields, pastures, and edges based on their availability was found. Forests were used significantly less than expected and hayfields significantly more than expected. The FH pair (Table 7) did not use hayfield any more or less than expected. 
TABLE 4: Frequency of occurrence of the Diamond Pond harrier pair in the habitats surrounding the nest site.

$\begin{array}{llccc}\text { Habitat } & \begin{array}{l}\text { Fraction } \\ \text { of total }\end{array} & \text { Observations } & \text { of } \\ \text { acreage } & \text { harriers } & \begin{array}{l}\text { Fraction } \\ \text { observed } \\ \text { in each } \\ \text { habitat }\end{array} & \begin{array}{c}\text { Expected } \\ \text { number of } \\ \text { observ. } \\ \text { in each } \\ \text { habitat }\end{array}\end{array}$

\begin{tabular}{lrrrr}
\hline Forest & .536 & 3 & .071 & 23 \\
Hay & .168 & 27 & .643 & 7 \\
Old Field & .141 & 3 & .071 & 6 \\
Pasture & .130 & 2 & .048 & 6 \\
Edges & .026 & 7 & .167 & 1 \\
Total & & 42 & & 43 \\
\hline
\end{tabular}


TABLE 5: 958 Confidence intervals on the fraction of occurrence of the Diamond Pond pair.

\begin{tabular}{|c|c|c|c|c|}
\hline Habitat & $95 \% \mathrm{Cor}$ & nfidence & Interval * & Conclusion \\
\hline Forest & 0.0000 & -.1728 & $(.536)$ & $\begin{array}{l}\text { Forest used } \\
\text { significantly less }\end{array}$ \\
\hline Hay & 0.4530 & -.8330 & $(.168)$ & $\begin{array}{l}\text { Hay used } \\
\text { significantly more }\end{array}$ \\
\hline old Field & 0.0000 & -.1728 & $(.141)$ & $\begin{array}{l}\text { No significant } \\
\text { difference }\end{array}$ \\
\hline Pasture & 0.0000 & -.1328 & $(.130)$ & $\begin{array}{l}\text { No significant } \\
\text { difference }\end{array}$ \\
\hline Edges & 0.0191 & -.3149 & $(.026)$ & $\begin{array}{l}\text { No significant } \\
\text { difference }\end{array}$ \\
\hline
\end{tabular}

* The values in parentheses represent the fraction of total acreage from Table 4. See text for explanation of confidence intervals. 
TABLE 6: Frequency of occurrence of the Forbes Hill harrier pair in the habitats surrounding the nest site.

$\begin{array}{ccccc}\text { Habitat } & \begin{array}{l}\text { Fraction } \\ \text { of total } \\ \text { acreage }\end{array} & \begin{array}{c}\text { Observations } \\ \text { of } \\ \text { harriers }\end{array} & \begin{array}{c}\text { Fraction } \\ \text { observed } \\ \text { in each } \\ \text { habitat }\end{array} & \begin{array}{c}\text { Expected } \\ \text { of observer of } \\ \text { in each } \\ \text { habitat }\end{array}\end{array}$

\begin{tabular}{lrrrr}
\hline Hay & .268 & 38 & .3250 & 31 \\
Forest & .517 & 32 & .2740 & 61 \\
Shrub & .141 & 8 & .0684 & 17 \\
Edges & .036 & 23 & .1970 & 4 \\
Logged & .032 & 16 & .1370 & 4 \\
Total & & 117 & & 117 \\
\hline
\end{tabular}


TABLE 7: 95\% confidence intervals on the fraction of occurrence of the Forbes Hill pair.

Habitat

95\% Confidence Interval* Conclusion

\begin{tabular}{llll}
\hline Hay & $.2103-.4397$ & $(.268)$ & $\begin{array}{l}\text { No significant } \\
\text { difference }\end{array}$ \\
Forest & $.1647-.3833$ & $(.517)$ & $\begin{array}{l}\text { Forest used } \\
\text { significantly less } \\
\text { Shrub used }\end{array}$ \\
Edges & $.0066-.1302$ & $(.141)$ & $\begin{array}{l}\text { Shrunificantly less } \\
\text { significanty more }\end{array}$ \\
Logged & $.0996-.2944$ & $(.036)$ & $\begin{array}{l}\text { Edge used } \\
\text { significantly } \\
\text { Logged used }\end{array}$ \\
\end{tabular}

* The values in parentheses represent the fraction of total acreage from Table 6 . 
Forest and shrub habitats were used significantly less than expected. Edges and logged habitats were used significantly more than expected.

For comparison, Table 8 contains the number of seconds and the fraction of total hunting time that the Diamond Pond and Forbes Hill pairs spent in each habitat type. The results are similar, whether duration or frequency are used, except for the FH pair's use of forests, and the DP pair's use of old fields.

\section{Hunting Behavior}

The Friedman test was used to determine whether males or females preferred a particular hunting behavior. These analyses were conducted on duration data. Female use of circling, diving between trees, transect, ground hunt, hover fly, dipping and border following was tested. Quartering flight was not included because females were never observed using this behavior. The results of the pairwise comparison (Table 9) showed that females spent significantly more time using border following and circling behaviors than ground hunting; transect flight was used for significantly longer periods than either diving between trees or ground hunting (Friedman's pairwise test, p < $.05) 1$.

Males were tested for differences in use between the same behaviors as females with two exceptions; males were never observed using ground hunting behavior but did use quartering behavior. The results of the pairwise 
TABLE 8: Habitat preference of the Diamond Pond and Forbes Hill pairs, based on time spent over the habitats surrounding nest site (data presented in total seconds and fraction of total hunting time).

\section{Diamond Pond Pair:}

Habitat

Total Seconds Spent Over Each Habitat (Fraction of total hunting time)

Forest

Hayfield

old Field

Pasture

Edges

Total

\section{$35(.029)$}

$859(.704)$

$215(.176)$

$0 \quad(.000)$

$112(.092)$

1221

\section{Forbes Hill Pair:}

Habitat Total Seconds Spent Over Each Habitat (Fraction of total hunting time)

Forest

Hayfield

Shrub wetland

Logged

Edges

Total

$$
\begin{array}{ll}
1552 & (.372) \\
1059 & (.254) \\
348 & (.083) \\
725 & (.174) \\
492 & (.118)
\end{array}
$$

4176 
TABLE 9: Friedman pairwise comparison of female hunting behavior preference based on duration.

\begin{tabular}{|c|c|c|c|c|c|c|c|}
\hline \multicolumn{2}{|c|}{$\begin{array}{c}\text { CIR } \\
(62.0)\end{array}$} & \multirow{2}{*}{$\begin{array}{c}\text { DBT } \\
(44.5) \\
17.5\end{array}$} & \multirow{2}{*}{$\begin{array}{r}\text { TRN } \\
(63.0) \\
1.0\end{array}$} & \multirow{2}{*}{$\begin{array}{c}\text { GDV } \\
(35.5) \\
26.5 *\end{array}$} & \multirow{2}{*}{$\begin{array}{c}\text { HFL } \\
(51.0) \\
11.0\end{array}$} & \multirow{2}{*}{$\begin{array}{c}\text { DIP } \\
(48.0) \\
14.0\end{array}$} & \multirow{2}{*}{$\begin{array}{r}\text { BFL } \\
(60.0) \\
2.0\end{array}$} \\
\hline $\begin{array}{l}\text { CIR } \\
(62.0)\end{array}$ & 0.0 & & & & & & \\
\hline $\begin{array}{l}\mathrm{DBT} \\
(44.5)\end{array}$ & - & 0.0 & 18.5 * & 9.0 & 6.5 & 3.5 & 15.5 \\
\hline $\begin{array}{l}\text { TRN } \\
(63.0)\end{array}$ & - & - & 0.0 & $27.5 *$ & 12.0 & 15.0 & 3.0 \\
\hline $\begin{array}{l}\text { GDV } \\
(35.5)\end{array}$ & - & - & - & 0.0 & 15.5 & 12.5 & 24.5 * \\
\hline $\begin{array}{l}\text { HFL } \\
(51.0)\end{array}$ & - & - & - & - & 0.0 & 3.0 & 9.0 \\
\hline $\begin{array}{l}\text { DIP } \\
(48.0)\end{array}$ & - & - & - & - & - & 0.0 & 12.0 \\
\hline $\begin{array}{l}\text { BFL } \\
(60.0)\end{array}$ & - & - & - & - & - & - & 0.0 \\
\hline
\end{tabular}

Rank sums (of duration) in parentheses; table values denote differences between paired rank sums.

* Denotes significant difference between the rank sums at the $\mathrm{p}<.05$ level.

Explanations of abbreviations:

CIR: circling

DBT: diving between trees

TRN : transect

GDV: ground hunting

HFL: hover flying

DIP: dipping

BFL: border following 
comparison (Table 10) indicated that males spent significantly more time using transect behavior than all of the other behaviors (quartering, hover flying, dipping, border following, circling and diving between trees; Friedman's pairwise test, $\mathrm{p}<.05$ ).

To determine if males and females select hunting behaviors differently, a Wilcoxon two-sample test was performed using duration data from the following behaviors: circling, diving between trees, transect, hover flying, dipping, and border following. Ground hunting and guartering were omitted from analyses because of the lack of data for males and females. Females spent significantly more time using circling behavior than males (Wilcoxon test, $p<.05)$. No difference was found for male/female use of other behaviors (Wilcoxon test, $p>.05$ ). The amount of time birds spent using each hunting behavior is presented in Appendix F2.

\section{Flight Altitude}

Friedman's test was used to determine if males and females preferred a particular flight altitude. I used duration data for these analyses. For females, all altitude categories were used: low, medium, tree-top, above-tree, low/medium, medium/tree-top, and treetop/above-tree. Pairwise comparison (Table 11) showed that; l) significantly more time was spent using medium altitude than medium/tree-top; 2) significantly more time was spent using tree-top altitude than low/medium, 
TABLE 10: Friedman pairwise comparison of male hunting behavior preference based on duration.

\begin{tabular}{|c|c|c|c|c|c|c|c|}
\hline $\begin{array}{l}C \\
(6\end{array}$ & $\begin{array}{l}\text { IR } \\
4.01\end{array}$ & $\begin{array}{l}\text { DBT } \\
(62.0)\end{array}$ & $\begin{array}{c}\text { TRN } \\
(102.0)\end{array}$ & $\begin{array}{l}\text { QUR } \\
(57.5)\end{array}$ & $\begin{array}{l}\text { HFL } \\
(59.0)\end{array}$ & $\begin{array}{l}\text { DIP } \\
(58.0)\end{array}$ & $\begin{array}{l}\text { BFL } \\
(73.5)\end{array}$ \\
\hline $\begin{array}{l}\text { CIR } \\
(64.0)\end{array}$ & 0.0 & 2.0 & $38.0 *$ & 6.5 & 5.0 & 6.0 & 9.5 \\
\hline $\begin{array}{l}\text { DBT } \\
(62.0)\end{array}$ & - & 0.0 & $40.0 *$ & 4.5 & 3.0 & 4.0 & 11.5 \\
\hline $\begin{array}{l}\text { TRN } \\
(102.0)\end{array}$ & - & - & 0.0 & $44.5 *$ & 43.0 * & 44.0 * & 28.5 * \\
\hline $\begin{array}{l}\text { QUR } \\
(57.5)\end{array}$ & - & - & - & 0.0 & 1.5 & 0.5 & 16.0 \\
\hline $\begin{array}{l}\text { HFL } \\
(59.0)\end{array}$ & - & - & - & - & 0.0 & 1.0 & 14.5 \\
\hline $\begin{array}{l}\text { DIP } \\
(58.0)\end{array}$ & - & - & - & - & - & 0.0 & 15.5 \\
\hline $\begin{array}{l}\text { BFL } \\
(73.5)\end{array}$ & - & - & - & - & - & - & 0.0 \\
\hline
\end{tabular}

Rank sums (of duration) in parentheses; table values denote differences between paired rank sums.

* Denotes significant difference between the rank sums at the $\mathrm{p}<.05$ level.

Abbreviations given in Table 9 . 
TABLE 11: Friedman pairwise comparison of female flight altitude preference based on duration.

\begin{tabular}{|c|c|c|c|c|c|c|c|}
\hline \multicolumn{2}{|c|}{$\begin{array}{l}\text { Low } \\
(54.0)\end{array}$} & \multirow{2}{*}{$\begin{array}{c}\text { Med } \\
(54.5) \\
0.5\end{array}$} & \multirow{2}{*}{$\begin{array}{c}\begin{array}{c}\text { Tree } \\
(66.5)\end{array} \\
12.5\end{array}$} & \multirow{2}{*}{$\begin{array}{c}\begin{array}{c}\mathrm{Ab} . \mathrm{Tr} \\
(59.5)\end{array} \\
5.5\end{array}$} & \multirow{2}{*}{$\begin{array}{l}\mathrm{L} / \mathrm{M} \\
(48.0) \\
6.0\end{array}$} & \multirow{2}{*}{$\begin{array}{c}\frac{M / T}{(37.0)} \\
17.0\end{array}$} & \multirow{2}{*}{$\begin{array}{c}\text { T/A } \\
(44.5) \\
9.5\end{array}$} \\
\hline $\begin{array}{l}\text { Low } \\
(54.0)\end{array}$ & 0.0 & & & & & & \\
\hline $\begin{array}{l}\text { Med } \\
(54.5)\end{array}$ & - & 0.0 & 12.0 & 5.0 & 6.5 & 17.5 * & 10.0 \\
\hline $\begin{array}{l}\text { Tree } \\
(66.5)\end{array}$ & - & - & 0.0 & 7.0 & $18.5 *$ & $29.5 *$ & 22.0 * \\
\hline $\begin{array}{l}\text { Ab.Tr. } \\
(59.5)\end{array}$ & - & - & - & 0.0 & 11.5 & $22.5 *$ & 15.0 \\
\hline $\begin{array}{l}\mathrm{L} / \mathrm{M} \\
(48.0)\end{array}$ & - & - & - & - & 0.0 & 11.0 & 3.5 \\
\hline $\begin{array}{l}M / T \\
(37.0)\end{array}$ & - & - & - & - & - & 0.0 & 7.5 \\
\hline $\begin{array}{l}T / A \\
(44.5)\end{array}$ & - & - & - & - & - & - & 0.0 \\
\hline
\end{tabular}

Rank sums (of duration) in parentheses; table values denote differences between paired rank sums.

* Denotes significant difference between the rank sums at the $\mathrm{p}<.05$ level.

Explanation of abbreviations:

Med: medium height

Tree: tree-top

$\mathrm{Ab}$. $\operatorname{Tr}$. : above-tree

$\mathrm{L} / \mathrm{M}:$ low/medium

$M / T$ : medium/tree-top

$\mathrm{T} / \mathrm{A}$ : tree-top/above-tree 
medium/tree-top, and tree-top/above-tree; and 3) that significantly more time was spent using above-tree than medium/tree-top (Friedman's pairwise test, p 8 .05).

Males did not spend equal amounts of timein each flight altitude category (Table 12). Medium/tree-top altitude was omitted from the analysis because of the low number of observations for this category. The results of the pair-wise comparison showed that males spent significantly more time using low altitude flight than above-tree and tree-top/above-tree altitudes (Iriedman's pair-wise test, $p<.05)$.

To determine whether males and females select flight altitude categories differently, a wilcoxon two-sample test was performed, using duration data from all categories except medium/tree-top (this category was omitted because of the lack of data for males and females). Fenales spent significantly more time than males using above-tree altitude, and males spent significantly more tine using low/medium altitude than females $(p<.05)$. The amount of time birds spent using each flight altitude is presented in Appendix F3.

Figure 1 shows the relationship between the height of the vegetation and the flight altitude used by both female and male harriers pooled. There were not enough data to permit a separate analysis of males and females. Harriers appeared to increase their flight altitude with increasing height of vegetation. Harriers spent more time using low and medium flight altitude in hayfields; the highest flight 
TABLE 12: Friedman pairwise comparison of male flight altitude preference based on duration.

\begin{tabular}{|c|c|c|c|c|c|c|}
\hline & $\begin{array}{l}\text { Low } \\
(88.5)\end{array}$ & $\begin{array}{l}\text { Med } \\
(74.0)\end{array}$ & $\begin{array}{l}\text { Tree } \\
(75.0)\end{array}$ & $\begin{array}{l}\mathrm{Ab} \cdot \mathrm{Tr} \\
(64.5)\end{array}$ & $\begin{array}{l}\mathrm{L} / \mathrm{M} \\
(78.0)\end{array}$ & $\begin{array}{l}\mathrm{T} / \mathrm{A} \\
(61.0)\end{array}$ \\
\hline $\begin{array}{l}\text { Low } \\
(88.5)\end{array}$ & 0.0 & 14.5 & 13.5 & $24.0 *$ & 10.5 & $27.5 *$ \\
\hline $\begin{array}{l}\text { Med } \\
(74.0)\end{array}$ & - & 0.0 & 1.0 & 9.5 & 4.0 & 13.0 \\
\hline $\begin{array}{l}\text { Tree } \\
(75.0)\end{array}$ & - & - & 0.0 & 10.5 & 3.0 & 14.0 \\
\hline $\begin{array}{l}\mathrm{Ab} \cdot \mathrm{Tr} \\
(64.5)\end{array}$ & - & - & - & 0.0 & 13.5 & 3.5 \\
\hline $\begin{array}{l}\mathrm{L} / \mathrm{M} \\
(78.0)\end{array}$ & - & - & - & - & 0.0 & 17.0 \\
\hline $\begin{array}{l}T / A \\
(61.0)\end{array}$ & - & - & - & - & - & 0.0 \\
\hline
\end{tabular}

Rank sums (of duration) in parentheses; table values denote difference between paired rank sums.

* Denotes significant difference between the rank sums at the $\mathrm{p}<.05$ level.

Abbreviations given in Table 11 . 
FIGURE 1: The flight altitude used by all harriers over each habitat type, based on duration.

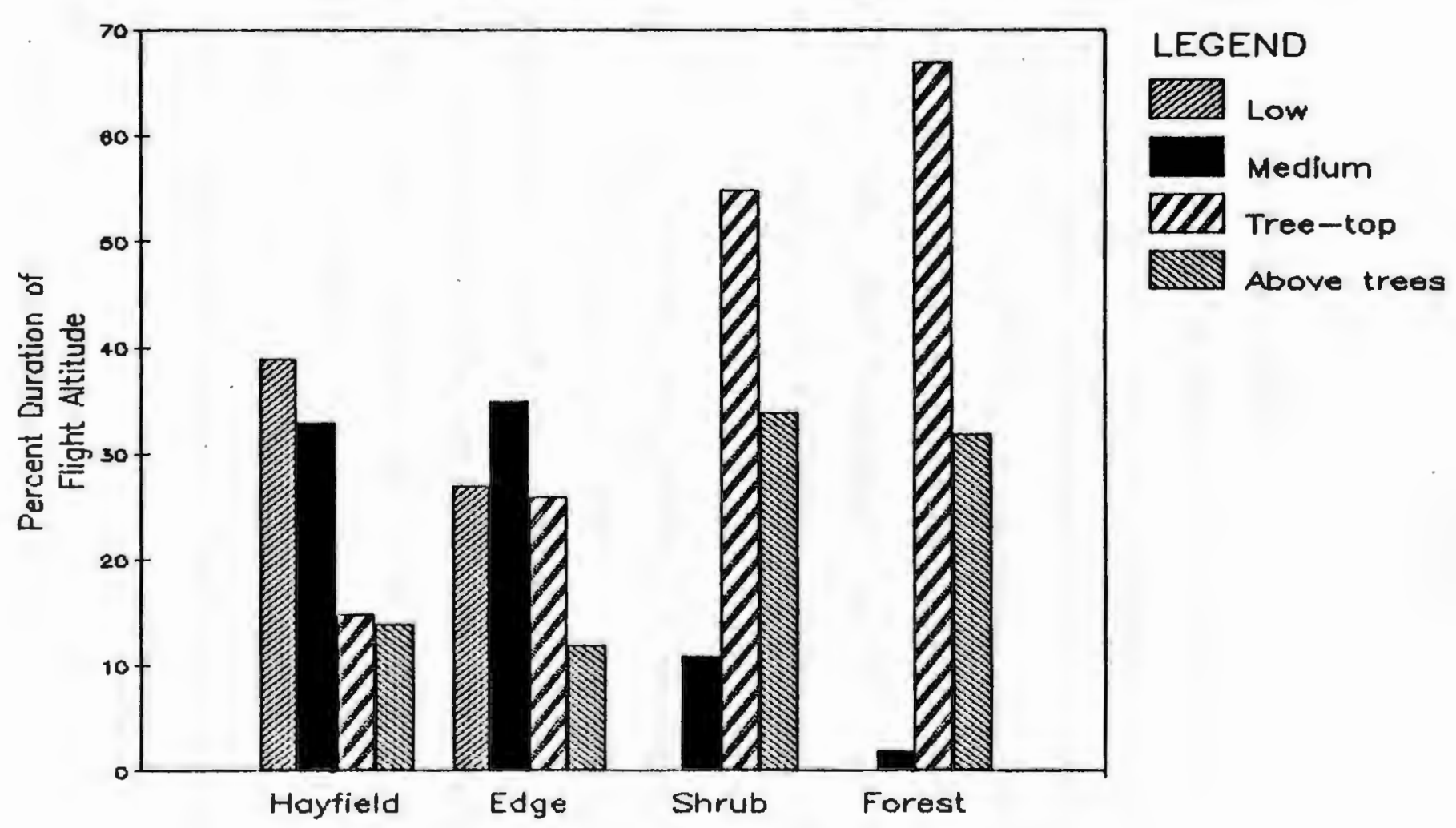


altitudes were observed primarily in forest. When harriers hunted in habitats comprised of vegetation of varying heights (edge and shrub habitats), all flight altitudes were used.

\section{Mammal Abundance}

Results from live-trapping two early and two late successional old fields and two hayfields suggested that meadow voles (Microtus pennsylvanicus) were not abundant at the study area during my sampling period, from June 30 to August 22, in 1985 (Table 13). Four voles were caught in six fields (Table 14), and this accounted for 7.7 percent of all individuals captured on all fields. Three out of the four voles were trapped at Moose Field which, unlike other fields, was trapped along the forest/field edges.

In the following discussion, the results from Moose Field are not included because of the different sampling method used. The two most abundant small mammals trapped on five fields were Blarina brevicauda (52.9\%) and Peromyscus spp. (23.5\%); however, low numbers of small mammals were trapped on all fields, regardless of successional stage. Capture success for the five fields was low, only $1.5 \%$

\section{Pellet Analysis}

The results of the analysis of the prey remains and pellets collected at the four nest sites in 1985 (DP, MM, $\mathrm{FH}, \mathrm{AL})$ are contained in Appendices Hl-H4. Data from these 
TABLE 13: Results of mammal trapping in six fields in coos County, 1985: Presented by field.

Field Habitat New Individuals/Species/Trap-Night*

Moose** Hay Field

$35 / 208 * * *$ :

1 Blarina brevicauda

4 Peromyscus spp.

3 Microtus pennsylvanicus

6 Napaeozapus insignis

20 Zapus hudsonius

1 unknown zapodid

Foss

old Field

(early

successional)

2/234:

2 Blarina brevicauda

Bushwack old Field

llate

successional)

3/203:

1 Condylura cristata

1 Peromyscus spp.

1 Clethrionomys gapperi

Treehouse Hay Field

2/230:

2 Peromyscus spp.

Shrew

old Field

l late successional)

7/206:

6 Blarina brevicauda,

1 Microtus pennsylvanicus

Access old Field (early successional)

3/233:

1 Zapus hudsonius,

1 Peromyscus spp.

1 Blarina brevicauda

Total New Individuals Per Total Trap-Nights: 52/1,314

* Sprung traps have been excluded from this value.

** Moose Field was the only field trapped along the edge.

*** Includes one trapping period where sprung traps were mistakenly included.

Foss, Bushwack, Shrew and Access were analyzed for vegetation cover and species density and frequency (Appendix C). 
TABLE 14: Results of mammal trapping in coos county, 1985: Presented by species.

Species

Total Number Trapped/Species
Fraction of Total ( 8 )
Zapus hudsonius

Blarina brevicauda

Peromyscus spp.

Napaeozapus insignis

Microtus pennsylvanicus

Clethrionomys gapperi

Condylura cristata

Z. hudsonius or

N. insignis

Total
21

40.4

10

19.2

8

15.4

6

11.5

4

7.7

1

1.9

1

1.9

1

1.9

52

100.0 
nests were pooled (Table 15) and are referred to in the following discussion. The results of the pellet analyses are presented in four sections. Sections A and B contain data from intact pellets, analyzed by the primary composition of each pellet (fur, feathers, scales, etc.), and by the frequency of occurrence of each prey category (small mammal, microtine rodent, etc.). Section $\mathrm{C}$ contains the summary of the contents of pellet fragments. These data were separated from intact pellets because I could not be sure that the entire pellet was represented. Section D contains the summary of prey remains found at nests and ground roosts. I did not attempt to derive quantitative data on the number of individuals represented in each pellet because many pellets did not contain enough bony fragments with which to do so. Errington (1932), Craighead and Craighead (1956), and Schipper (1973) warned investigators of the difficulty of gaining accurate quantitative data from pellet analysis because hawks usually digest most of the bony remains of their prey. The primary constituents of most pellets were fur (61.5\% of all pellets) or feathers (15.4\%). Many pellets, however, contained varying amounts of fur, feathers, and snake scales. Plant fragments were found in $84.6 \%$ of the pellets and insect remains in $82.7 \%$.

At all four nests, small mammal prey was the most frequent component of intact pellets, with bird and snake remains second in importance. Skull fragments from the 
TABLE 15: Summary of pellets and prey remains found at four Northern Harrier nests, 1985.

$\begin{array}{lc}\text { A. Primary Constituents of Intact Pellets (N=52) } \\ \text { 1. >50\% fur: } & 32 * \\ \text { 2. >50\% feathers: } & 8 \\ \text { 3. 50\% fur, 50\% feathers: } & 7 \\ \text { 4. >50\% plant material: } & 1 \\ \text { 5. >50\% snake scales: } & 1 \\ \text { 6. 50\% fur, 50\% snake scales: } & 1 \\ \text { 7. 50\% feathers, 50\% plant material: } & 1 \\ \text { 8. 50\% fur, 50\% plant material: } & 1\end{array}$

B. Frequency of Occurrence of Prey Type in Intact Pellets

1. Small Rodent/Mammal

2. Family Zapodidae

3. Zapus hudsonius

4. Subfamily Microtinae

5. Microtus spp.

6. Tamias striatus

7. Blarina brevicauda

8. Bird (ali)

9. Order Passeriformes

10. Snake

11. Unidentified Bone Fragments

34

4

1

27

7

1

3

15

1

14

4

C. Summary of Pellet Fragment Contents: Smal1 rodent/mammal, family Zapodidae, Zapus hudsonius, subfamily Microtinae, Microtus spp., Microtus pennsylvanicus, Blarina brevicauda, unidentified bird and snake remains, unidentified bone fragments.

D. Summary of Prey Remains: Full-grown and young Tamiasciurus hudsonicus, small- and medium-sized birds, small- and medium-sized passerines, full-grown and young Ruffed Grouse, Common Flicker, American Robin, Bobolink, unidentified snake scales and skin, young Thamnophis sirtalis.

* Represents the number of intact pellets which were composed of the listed item. 
subfamily Microtinae occurred most frequently within the small rodent/mammal category. Because it was difficult to distinguish between the different species of Microtus which could occur at the study area, skull fragments were assigned to the genus only, with the exception of some skull remains found in pellet fragments. Bird remains were found in 15 of the 52 pellets; however, it was not possible to identify birds to order in most cases. Snake remains were found in 14 pellets, and were usually in the form of numerous vertebrae and scales.

Pellet fragments collected from nests and surrounding areas were analyzed qualitatively because I could not be sure I had found the entire pellet. Prey species found in pellet fragments were similiar to those found in intact pellets. In several pellet fragments it was possible to assign skull fragments to Microtus pennsylvanicus.

The results of the summary of prey remains found at nest sites were quite different from the pellet analysis. Small mammal remains such as B. brevicauda, Microtus spp. and $\underline{z}$. hudsonius were never found at nests or ground roosts, only in pellets. Prey remains were composed primarily of the skeletal parts of unidentified small- and medium-sized birds. It was often difficult to identify the avian component of prey remains. Bird species which were confirmed were Ruffed Grouse (Bonasa umbellus), Common Flicker (Colaptes auratus), American Robin (Turdus migratorius) and Bobolink (Dolichonyx oryzivorus). The 
remains of several young common garter snakes (Thamnophis sirtalis) were found at a ground roost at the Reed/Alex nest site. 


\section{DISCUSSION}

Hunting Habitat Selection and Hunting Behavior

\section{Habitat Selection}

Intersexual differences in the hunting habitat selection of $\underline{C}$. cyaneus has been observed in both breeding and non-breeding populations in North America (Bildstein 1978; Temeles 1986; Martin 1987) and Europe (Schipper et al. 1975; Schipper 1977). The factors responsible for these differences in habitat use were related to the following: utilization of different prey species by each sex during the breeding and non-breeding season (Schipper 1973; Bildstein 1978; Picozzi 1978, 1980); smaller nesting season ranges of females compared to males, resulting in female preference for the habitats surrounding nest sites (Schipper 1977; Martin 1987); and female exclusion of males from preferred hunting habitats during the winter (Temeles $1986)$.

To evaluate prey selection, hunting behavior and habitat selection in raptors, the difference in size between the sexes should be considered. In most raptor species the female is larger than the male, a phenomenon referred to as reversed sexual size dimorphism. The degree of the size dimorphism increases with the amount of fastmoving prey species present in the diet. As a result, carrion feeders exhibit little size dimorphism, and raptors belonging to the genus Accipiter, which feed almost entirely on birds, are the most strongly dimorphic (Newton 
1979). The harriers, including both the Northern and Hen Harriers, are also strongly dimorphic. The male Northern Harrier averages 367 grams, and the female 530 grams (Hamerstrom 1986). The male Hen Harrier averages 340 grams and the female 500 grams (Schipper 1973).

Male and female harriers also exhibit differences in wing structure (Nieboer in Bildstein 1978). In C. cyaneus, the male is considered more agile than the female because males have shorter wings and lower wing-loading ratios (Brown and Amadon 1968; Temeles 1986). Wing-loading is defined as the ratio of body weight to surface area of wings. Shorter wings and lower wing-loading are advantageous for short bursts of flight and increased maneuverability between trees. Males have been found to capture more agile prey than females (songbirds) and use a more "accipiter-like" flight style (Schipper et al. 1975; Bildstein 1978). Members of the genus Accipiter feed primarily on avian prey and inhabit woodlands.

In coos county I did not find significant differences between male and female use of four habitats: hayfield, forest, shrub and edges. When habitat preference within each sex was analyzed, females did not show any preference for a particular habitat. Males spent significantly more time over hayfields than forest, shrub habitats and edges. In the Netherlands, Schipper (1977) stated that Hen Harriers nested and hunted in coastal dunes and reeds. Females usually hunted in the habitats adjacent to nest 
sites. Males also hunted near nests, but were seen more frequently than females in the habitats situated outside of nesting areas (reeds, cultivated fields and grasslands). In Idaho, Martin (1987) also reported that females hunted in the habitats immediately surrounding the nest site (riparian and cultivated fields), however, female habitat use was not quantified. Males hunted farther from the nest than females, in riparian and shrub-steppe habitats, and cultivated fields.

I believe that differences between the results of my study in coos county and others are related primarily to the distribution of habitats at the study area. In coos County, although females were found nesting in shrub wetlands and old fields (Chapter 1), these habitats and others (hayfields, pastures, forests and logged areas) were also found scattered throughout the study area. Regardless of how far from nests males hunted, they would encounter the same habitat types as those situated near nests.

In addition to the distribution of habitats within the study area, differences between males and females with respect to habitat selection may have been decreased by the pooling of habitats. Logged areas, shrub wetlands and old fields (late successional stage) were analyzed as "shrub" habitats, because of the low number of observations over each habitat. More data are needed on the use of the various "shrub" habitats at the study area by both males and females.

In two European studies (Schipper 1973, 1977; Picozzi 
1978), breeding males and females selected different prey species. Males usually took lighter prey than females, such as small and medium-sized birds and voles. Females preyed upon a wider range of animals, but were able to take larger prey than males, e.g. grouse, pheasants, and young rabbits. Schipper (1977) found that differences between males and females with respect to habitat selection were related to differences in prey selection. I was unable to collect data on the prey selection of males and females, therefore, the effect of this parameter on the habitat selection of harriers in coos County is unknown.

The habitat preference of two pairs of harriers in coos county, based on the availability of habitat types within their hunting ranges, resulted in both the avoidance and preference of some areas. I found that harriers preferred open habitats, such as hayfields and edges, over forest and shrub. When all male harriers were pooled, they spent significantly more time over hayfields than shrub, forest or edges. Shrub and forest habitats may not have been strongly preferred because of the dense cover of the vegetation compared to hayfields. The selection of habitats by hunting raptors is often related to vegetation cover and not prey density (Southern and Lowe 1968; Wakeley 1979; Bechard 1982; Martin 1987). In Idaho, Martin (1987) found that male harriers shifted from alfalfa fields, where they preyed upon upon voles (Microtus spp.), to more open habitats (shrub-steppe) when the alfalfa reached a 
particular height. In coos county, prey species in open habitats, such as hayfields and edges, would be more visible to hunting birds than those in dense, shrubby habitats.

I found that male and female harriers spent $25 \%$ to $32 \%$ of their total hunting time over forests, although these habitats were not used significantly more than open habitats. Harriers in coos county appeared to hunt in forest habitats more frequently than has been reported in other studies (Schipper 1977; Watson 1977; Bildstein 1978). Schipper (1977) infrequently observed males hunting over conifer plantations outside of nest sites. Watson (1977), in Britain, found Hen Harriers hunting in conifer forests less than six meters high, or where these forests were interspersed with patches of open areas; however, woodland was generally avoided. I observed harriers hunting over both conifer and mixed conifer/deciduous forest, where trees ranged in height from 13 to 23 meters. Harriers often dived between trees while hunting over forests, which may indicate that they were attempting to flush birds from trees or pursue prey in open spots on the ground. I never observed harriers actually secure prey over these habitats. watson (1977) saw harriers capture birds while in flight over forests; harriers usually capture their prey on or near the ground.

Without data on the prey selection of harriers over forested habitats, it is difficult to determine why forest hunting occurred more often at coos County compared to 
other areas. Because the open habitats within the study area have been reverting to forest and brushy habitats since the early 1900 's, it is possible that harriers are being forced to hunt in less-preferred habitats and/or because these habitats were located adjacent to nest sites.

\section{Hunting Behavior and Flight Altitude}

Harriers in coos County exhibited several hunting behaviors which have not been reported in the literature, such as circling, diving between trees (DBT) and dipping flight. In addition, I found that quartering flight was only observed in males, and was infrequently used $1.7 \%$ of all males total hunting time). In other studies (Schipper et al. 1975; Schipper 1977; Bildstein 1978; Temeles 1986), both males and females often used quartering flight. Quartering flight has been observed more frequently in females than in males (Schipper 1977; Bildstein 1978; Temeles 1986); males used border folowing (BFL) and transect flight more than females, according to schipper (1977) and Temeles (1986). In Coos County, females exhibited a preference for transect, circling and BFL over other hunting behaviors; males spent more time using transect flight than other flight types. Females spent significantly more time than males using circling flight.

Similarities between both circling and DBT with quartering behavior can be seen. When DBT was observed, the birds often dived toward the ground while "quartering" over trees. Bildstein (1978) noted that harriers flew at 
higher speed when using BFL and transect flight than quartering. Although I did not determine flight speed for the various hunting behaviors, harriers also appeared to fly more slowly when using circling and/or DBT flight than transect and BFL. Harriers may have employed DBT, circling and quartering flights to investigate particular patches of terrain.

DBT flight appeared to be related to forest hunting in coos county. It occurred primarily over habitats which contained trees (forests and logged areas), and was associated with high flight altitudes (tree-top height). DBT may not have been reported in other studies of harrier hunting behavior (Schipper 1977; Watson 1977; Bildstein 1978; Temeles 1986) because forests were infrequently used or were unavailable.

Schipper et al. (1975) noted that Hen Harriers used different flight altitudes when hunting. He called this "undulating flight", where the harrier changes flight altitude and often speed. I observed that harriers at coos County flew at different flight altitudes when employing dipping and DBT behavior. Changes of altitude and flight speed may increase chances of surprising prey and be advantageous in vegetation of varying height.

I found that males exhibited a preference for low altitude flight, and spent significantly more time using low/medium flight altitude than females. Females appeared to show a slight preference for higher flight altitudes 
than males; they spent more time using medium, tree-top and above-tree height over other flight altitudes, and spent significantly more time than males using above-tree altitude. In Europe, during the breeding season, male harriers used low flight altitude most frequently (Schipper 1977). Data on female flight altitude selection was not provided. Schipper et al. (1975) and Temeles (1986) both noted that females used higher flight altitudes more frequently than males during winter months.

I found that harrier flight altitude was associated with vegetation height. Harriers spent more time using low flight altitude over short vegetation, and higher flight altitudes over tall vegetation. In habitats containing vegetation of varying heights, harriers used all flight altitudes. Schipper et al. (1975) and Schipper (1977) observed the same response to vegetation height by hunting Hen Harriers in both winter and breeding season studies. By increasing flight altitude as vegetation height increases, the harrier maintains its field of view into the vegetation.

For hunting harriers, and other raptors, a complex relationship exists among the hunting behavior used, flight altitude, the structure and height of the vegetation, the sex of the bird, prey abundance and vulnerability, and weather conditions (Schipper 1973, 1977; Schipper et al. 1975; Bildstein 1978; Janes 1985; Collopy and Bildstein 1987). Schipper et al. (1975) stated that a hunting harrier changes its hunting technique in response to 
characteristics of the vegetation and terrain, so that it may surprise prey. In coos County, harriers did not exhibit strong intersexual differences in habitat selection. Males and females may have employed distinct behavioral and flight altitude combinations, related to differences in prey selection and/or maneuverability between them. More data are needed to investigate quantitatively the relationship between sex of the harrier, hunting technique, and habitat and prey selection in coos County •

Harriers may have used previously unreported hunting methods in coos county because of the complexity of the vegetation structure and topography. Open habitats, such as hayfields and pastures, are frequently interrupted by small streams, hedgerows and patches of wetlands. Vegetation heights range from less than one meter in hayfields to approximately 20 meters in forests. In studies of the hunting behavior and habitat selection of harriers in North America and Europe, the topography did not appear to be as varied as that in coos County. Forested habitats either were not used by harriers or were unavailable (Schipper 1977; Bildstein 1978; Temeles 1986). Elevations in Ohio ranged from 229 to 335 meters above sea level (Bildstein 1978), and in coos county, from approximately 270 to 750 meters (Williams et al. 1943). Vegetation heights in the Netherlands (Schipper 1977) varied from .20 to 2.50 meters. In California, Temeles 
(1986) does not give the heights of the tallest vegetation, however, the study area was composed primarily of cropland. Harriers in coos county may have selected a variety of behaviors and flight altitude combinations to take advantage of the patchy and complex topography at the study area.

\section{Mamma 1 Abundance}

Although the various habitats sampled for small mammal abundance appeared able to support high numbers of mammals, only Moose Field, which was trapped along the edges, showed a high trap success. Meadow voles (M. pennsylvanicus) were not abundant on any of the fields sampled at the study area. Northern Harriers have been found to prey heavily on these voles during the breeding season (Hamerstrom 1969, 1979; Simmons et al. 1986a.b.). Abandoned fields and other disturbed habitats, with vegetation cover composed primarily of dense grasses or weeds, may support high densities of meadow voles and other small mammals (Craighead and Craighead 1956; Birney et al. 1976; Phelan and Robertson 1978; Baker and Brooks 1981; Hamerstrom $1986)$.

other than trapping results, high vole densities may be indicated by the following; 1) a high number of runways and holes present, 2) frequent piles of scats and/or cut grasses, 3) girdling of trees and shrubs, and 4) frequent sightings of voles when an area is surveyed on foot (Craighead and Craighead 1956; Hamerstrom 1986). Although 
runways were found in some fields, voles were never observed in them and were rarely seen when investigators were trapping or moving through fields to observe harriers. Some of the factors which may have accounted for the low number of animals trapped at the study area were that meadow voles were abundant but were reluctant to enter the traps (i.e. were trap-shy) and food was abundant (P. August, pers. comm., 1985); voles were at the low part of a population cycle or decline; and some habitats did not provide enough cover for voles to occur in high densities (Birney et all. (1976).

In coos County, hunting harriers did not prefer old fields over other habitat types. Hayfields were used significantly more than expected when all males were pooled, and by the Diamond Pond pair. Although small mammal abundance appeared low in both hayfields and old fields, harriers may have found prey more vulnerable in hayfields because cover was not as dense. More data are needed on mammal abundance in old fields and hayfields, in addition to prey selection of harriers in these habitats.

\section{Pellet Analysis}

Microtine rodents and small- and medium-sized birds were found with the highest frequency in pellets and as prey remains at nests and ground roosts. The remains of snakes were more difficult to assess with respect to their importance in harrier diets because skeletal remains were rarely found. These results were similar to European and 
North American studies of harriers where both mammal and bird prey were important in harrier diets (Craighead and Craighead 1956; Schipper 1973; Picozzi 1978, 1984; Toland 1985). Data from additional nests are needed to adequately assess the prey selection of harriers during the breeding season. 


\section{SUMMARY}

Differences between males and females with respect to hunting habitat selection, hunting behavior and flight altitude were varied. Males and females may have chosen similar hunting habitats because of the distribution of habitat types at the study area. Regardless of the distance birds traveled from the nest, they would encounter the same habitat types. Harriers preferred open habitats (hayfields, edges) over forests and shrub, probably because prey was more vulnerable where cover vegetation was not as dense.

New hunting behaviors were observed at the study area, such as circling, diving between trees and dipping flight. Harriers in coos County rarely used quartering flight, although this behavior was frequently seen in other studies of hunting harriers. I suggest that variations with respect to topography, habitat type and vegetation structure between my study area and others may have accounted for new behaviors.

Male harriers exhibited a preference for lower flight altitudes, and females appeared to spend slightly more time using higher flight altitudes. All harriers increased flight altitude as vegetation height increased. In habitats with vegetation of varying heights (edges and shrub), all flight altitudes were observed.

Data on prey selection and mammal abundance was limited, but it appeared from pellet analyses that the diet 
of harriers was varied. Microtine rodents and small- and medium-sized birds were most frequently seen in pellets and as prey remains. 
CHAPTER THREE:

THE STATUS OF NORTHERN HARRIERS IN NEW ENGLAND: POSSIBLE MANAGEMENT STRATEGIES 


\section{Introduction}

The purpose of this chapter is twofold: to determine the status of the population of Northern Harriers breeding in coos county, and to discuss management strategies which can be used at the study area and throughout New England. These subjects will be evaluated by investigating the following: 1) a comparison between the historic and current distribution of harriers in New England, 2) the factors responsible for declines in harrier populations throughout North America, 3) data collected on nest density and fledgling production, hunting habitat selection, nest ecology, nesting season ranges and feeding ecology of breeding harriers in coos County, and 4) negative impacts from both human-related activities (logging, off-road vehicle use and housing construction) and land use changes (natural succession from open habitats to forest on abandoned farmland) at the study area. These parameters have been evaluated in other studies of threatened raptor species throughout Europe and North America (Hamerstrom 1969; Fyfe and Armbruster 1977; Watson 1977; Newton 1979; Grubb et a‥ 1983; Dunne 1984).

\section{The Historic Distribution of Northern Harriers in New England}

The Northern Harrier was a common breeding raptor in New England and other northeastern coastal states in the mid-1800's and early 1900's (Baird et al. 1860, 1874; Bendire 1892; Cory 1899; Hoffman 1910). Forbush (1929) noted that the number of breeding harriers was beginning to 
decrease in New England during the early 1900's, although the species was still considered fairly common. During the summer months harriers were found in extensive meadows, swampy uplands (Cory 1899; Hoffman 1910), and in salt marshes and river valleys (Forbush 1929). Forbush stated that harriers nested on Cape cod and were extremely common breeders on Martha's Vineyard.

In New Hampshire, Northern Harriers were common breeders in the southern counties (Hillsborough, Strafford, Belknap and Merrimack), and in the White Mountain and Umbagog region. Harriers began to decrease in New Hampshire in the early 1900's (Smith and Choate 1985) which coincided with the declines in farming (Williams et al. 1943; Russell 1982). After this initial decrease, harrier populations continued to decline because of pesticide poisoning and further reductions in habitat quality and quantity (Smith and Choate 1985).

The Current Status of the Northern Harrier in North America, with Special Reference to New England

According to population assessments in recent years (Arbib 1973; Tate 1981; Evans 1982; Tate and Tate 1982), Northern Harrier populations have declined or are unstable in many parts of North America. The harrier has been on the Blue List (an "early warning" system published by American Birds and used to identify species which have experienced serious, noncyclical population declines) since 1972. Northern Harrier populations continue to decrease 
(Tate 1986). Reports of declines have been received from several parts of the United States and Canada, including the Northeastern Maritime region, the grasslands of the Midwest and West, and the southern part of the West coast. In addition to New England, harriers have been placed on lists of special concern in Missouri (Toland 1985) and New York (M. England, Long Island University, pers. comm., 1987), and have experienced serious declines in New Jersey (Dunne 1984) and North and South Dakota (Duebbert and Lokomoen 1977 ).

Although the factors contributing to the decrease in breeding harriers vary from region to region, habitat destruction throughout their range and the reforestation of open land in New England are considered the most significant (Evans 1982; Dunne 1984; Laughlin and Kibbe 1985; Hamerstrom 1986). Since the mid-1950's, losses of wetlands have increased dramatically because of agricultural expansion, and residential and industrial development (Tiner 1984). In New York, Connecticut and New Jersey, where harrier numbers have declined, losses of coastal wetlands are especially significant (Frayer et al. 1983; Niering in Tiner 1984). Inland wetlands are also vulnerable in New England and the Northeast, although coastal wetlands are now protected. In the Midwest, agricultural development still threatens inland wetlands (Tiner 1984 ).

In New England, much of the open habitats created by the farming industry since the $1800^{\prime}$ s have reverted to 
forest (Williams et al. 1943; Russell 1982; Frieswyk and Malley 1985; Laughlin and Kibbe 1985). In the midwestern and western United States (Duebbert and Lokomoen 1977; Toland 1985; Hamerstrom 1986), the overgrazing of pastures and conversion of grasslands to crops has destroyed nesting habitat and decreased populations of prey species such as small mammals.

Pesticide poisoning and human disturbance have been implicated in harrier declines in New Jersey (Dunne 1984), Wisconsin (Hamerstrom 1969, 1979), Vermont (Laughlin and Kibbe 1985) and New Hampshire (Smith and Choate 1985). Pesticide use in Wisconsin in the mid-1960's caused sharp decreases in the number of breeding harriers (Hamerstrom 1969, 1979). Increased recreational use of the New Jersey coast was reported by Dunne (1984) to contribute to a decrease in breeding harriers. Human disturbance may also be important in heavily-used areas of the New England coast, such as Rhode Island, Massachusetts and the offshore islands (P. Serrentino, pers. obs.).

Arbib (1973) stated that harrier populations had declined more dramatically in eastern North America than in other parts of the continent. In New England, harriers were faced with both the destruction of traditional breeding areas, such as coastal and inland wetlands, and reforestation of previously open agricultural habitats. The amount of open 1 and in New England reached a peak in the southern regions (Massachusetts, Connecticut and Rhode 
Island) in the 1820's and in the northern states (Maine, Vermont and New Hampshire) around 1900, as forests were cleared for agriculture. With declines in the farming industry, reforestation began in the late $1800^{\circ} \mathrm{s}$ in southern New England and early 1900's in the north (Hawes 1923; Gould and Reidel 1979; Russell 1982). Harriers may have begun breeding in the open habitats created by agriculture during the early 1800 's, since these raptors were considered common breeders by the mid-1800's (Bendire 1892; Cory 1899; Hoffman 1910). The decrease in harrier numbers in southern New England in the early 1900's coincided with the loss of agricultural habitats.

Land-use patterns in coos County followed the same pattern reported above. Subsistence farming occurred in the county until approximately 1880, when the dairy farming industry began to expand. The amount of open land in the county peaked around 1900, when 29 percent of the total land area was comprised of farmland (Williams et al. 1943). The number of farms in the county began to decrease in the early 1900's because farmers could not compete with their counterparts in the west, and because of the emigration of people to urban areas (Williams et al. 1943; Frieswyk and Malley 1985).

Although no data are available on the historic distribution of breeding harriers in coos County, these raptors may have been most abundant during the early 1900's when the number of dairy farms was the highest. As the amount of farmland has decreased in coos county, harriers 
have become confined to the open habitats within the $32,340-$ hectare study area and other large tracts of farmland and shrubby habitat found along the connecticut River Valley. Between 1935 and 1982, the amount of farmland in coos county decreased from 29 percent to 4 percent (U.S. Department of Commerce 1984; Frieswyk and Malley 1985).

\section{An Evaluation of the Breeding Biology of the Northern Harrier in coos County}

The density and fledgling production of breeding harriers in coos county was determined for comparison with data collected on other populations in North America and Europe. The mean number of young fledged for all nests (includes suspected failures and successful nests) was 1.9 to 2.3 , and for successful nests only was 2.6 to 2.7 , for 1984 and 1985. The density of breeding harriers ranged from 5.0 to $6.7 \mathrm{~km}^{2}$ per female. Although more data are needed, the fledgling production and density of breeding harriers in coos county does not appear to be signficantly lower than that reported from studies of harrier populations which were not suffering from severe population declines (Balfour and Cadbury 1975, 1979; Picozzi 1978; Hamerstrom et al. 1985; Simmons et al. 1986a.b.).

Harriers have nested in the same general location at the study area from year to year (Table 1). Because birds were not marked, I could not be sure if the same female or male was involved. The following sites have been used in 
TABLE 1: Fledgling production of Northern Harriers in Coos County, 1983 to 1987 .

\begin{tabular}{|c|c|c|}
\hline Nest Location & $\begin{array}{l}\text { Years Area Used } \\
(1982 \text { TO 1987) }\end{array}$ & $\begin{array}{l}\text { Fledglings/Female } \\
\text { (Source of Data) }\end{array}$ \\
\hline $\begin{array}{l}\text { Brown/ } \\
\text { Cleveland school }\end{array}$ & $\begin{array}{l}1983 \\
1984 \\
1985\end{array}$ & $\begin{array}{ll}3 & (\text { ESP }) \\
2 & (E S P) \\
2 & (P S)\end{array}$ \\
\hline Cedar Brook & 1983 & 1 or 2 (HD) \\
\hline Cilley Hill & 1987 & 1 (HD) \\
\hline Clarksville & 1984 & 3 (ESP) \\
\hline Diamond Pond & $\begin{array}{l}1983 \\
1984 \\
1985 \\
1986 \\
1987\end{array}$ & $\begin{array}{ll}3 & \text { (HD) } \\
4 & \text { (PS) } \\
4 & \text { (PS) } \\
2 & \text { (PS) } \\
2 & \text { (HD) }\end{array}$ \\
\hline Forbes Hill & $\begin{array}{l}1984 \\
1985 \\
1987\end{array}$ & $\begin{array}{ll}3 & \text { (PS) } \\
3 & \text { (PS) } \\
3 & \text { (HD) }\end{array}$ \\
\hline Hall stream & 1983 & 2 (HD) \\
\hline Killam/Columbia & $\begin{array}{l}1982 \\
1983 \\
1984\end{array}$ & $\begin{array}{ll}1 & \text { or } 2 \\
1 & (E S P) \\
1 & (E S P)\end{array}$ \\
\hline Mudget Mountain & $\begin{array}{l}1984 \\
1985 \\
1987\end{array}$ & $\begin{array}{ll}3 & (H D) \\
1 & (P S) \\
3 & (H D)\end{array}$ \\
\hline Piper Hill & 1985 & 1 (HD) \\
\hline pleasant View & 1982 & 1 (ESP) \\
\hline Reed/Alex & $\begin{array}{l}1984 \\
1985 \\
1986\end{array}$ & $\begin{array}{ll}1 & \text { (PS) } \\
3 & \text { (PS) } \\
2 & \text { (PS) }\end{array}$ \\
\hline South Hill & 1987 & 1 (HD) \\
\hline $\begin{array}{l}\text { Washburn/ } \\
\text { Union School }\end{array}$ & $\begin{array}{l}1982 \\
1983 \\
1984\end{array}$ & $\begin{array}{ll}3 & (\text { ESP }) \\
1 & (\text { HD }) \\
1 & (E S P)\end{array}$ \\
\hline
\end{tabular}

* PS: Present Study

HD: Harrier Day

ESP: Volunteer, New Hampshire Endangered Species Program 
Coos County for two years or more: Brown/Cleveland School, Diamond Pond, Forbes Hill, Mudget Mountain, Reed/Alex, and Washburn/Union School. Residents of Forbes Hill reported that harriers nested in the same area in the late 1970's as in 1984 (D. Killam, Endangered Species Program, pers. comm., 1985). Many raptor species use the the same nest site every year, although not always the same nest (Newton 1976); this phenomenon was reported for Hen Harriers in Orkney (Balfour and Cadbury 1979), Northern Harriers in Alberta and Saskatchewan (Sealy 1967), and other raptor species (Janes 1984; White and Thurow 1985; Newton et al. $1986)$.

The factors responsible for nest site selection by Northern Harriers in Coos County are unknown. Data collected in other studies suggest that safety from terrestrial predators (Hamerstrom and Kopeny 1981; Simmons and Smith 1985), the density of prey in nearby areas (Simmons and Smith 1985) and the distribution of suitable nesting habitat (Balfour and Cadbury 1979) contribute to nest site selection. All nests that I found in 1984 and 1985 were located in dense shrubs which may have deterred predators. Nests were also placed adjacent to open habitats such as hayfields, pastures and shrubby areas, where both males and females were observed hunting. Because harriers in coos county exhibited a tendency to occupy traditional breeding sites for more than one year, these sites should continue to be monitored to 
determine if vacancies of several nest sites occur over a long time period. A decrease in the number of nesting harriers over several years, associated with high prey abundance and without major changes in land-use practices at the study area, would signal a serious, noncyclical population decline.

During 1986 fledglings were found at only two nest sites. Although the study area was not surveyed as extensively as in 1984 and 1985, this represents the lowest number of successful nests reported since the monitoring program began in 1981. In 1987 the population produced approximately 10 fledglings from five nesting sites. Because harriers normally experience fluctuations in the number of pairs nesting, especially those populations that depend on cyclic prey, such as meadow voles, the low densities observed in 1986 were probably not indicative of a serious population decline. The decrease may have been caused by low densities of several prey species, and/or high predation on eggs and young. Data on the food habits of breeding harriers were not available in 1986, and the information collected in 1985 was not extensive enough to permit an accurate assessment of the effect of meadow vole abundance on breeding harriers.

More data on several population parameters, such as age of breeders, mortality of young and adults, prey base, patterns of occupation of nest sites and the occurrence of polygyny would provide additional information for the assessment of the status of the harrier population. 
Increased censusing of the study area for new breeding sites and missed nests would improve density and fledgling production estimates. With the data collected from the population since 1982, the harrier population at the study site seems stable, although vulnerable to further decreases in open habitats.

\section{Possible Management Plans for Harriers in Coos County} According to Olendorff and Kochert (1977), the protection of key habitats should be the first step in maintaining a declining or threatened population. Negative impacts to nesting raptors, such as desertion of nests, from human activities should be lessened or stopped completely. Newton (p. 264, 1979) stated that habitat destruction has accounted for the greatest reductions in raptor populations. The serious decline in the number of breeding harriers throughout New England coincides with the loss of nesting and hunting habitats from both reforestation of open habitats and the destruction of inland and coastal wetlands (Laughlin and Kibbe 1985; Smith and Choate 1985; P. Serrentino, pers. obs.).

The major industries in coos county consist of dairy farming, small timber operations, and tourism (J. Riff and A. Schmidt, Coos County Agricultural Stabilization and Conservation Service (ASCS), pers. comm., 1986). The largest threat to the maintenance of the breeding population is the changing land-use patterns in the county. Other factors which could affect the breeding success of 
harriers are disturbance from logging and farming activities, off-road vehicle traffic, and housing construction. Presently, threats to harriers from the above activities are low. A management plan for harriers must first address the protection of the habitats neccessary to maintain the present population and minimize threats to nesting birds.

A management plan for harriers in coos County would consist of the following recommendations: 1) active maintenance of old fields and shrubby habitats which have supported nesting harriers since the monitoring program began, 2) a public education campaign to inform people of the status of harriers in New Hampshire, 3) notification of landowners who have birds nesting on their property of the presence of these birds, and request of their cooperation in maintaining the integrity of the nest site, 4) expansion of current monitoring programs, and 5) protection of the areas surrounding harrier nests from human disturbance.

Harrier populations in coos County utilize the open habitats provided by dairy farms and logging activities. Data collected on hunting habitat selection (Chapter 2) and nest ecology (Chapter 1) suggest that hayfields, edges and logged areas were important for hunting harriers and shrub wetlands and old fields for nesting birds. Because the dairy industry continues to decline (J. Riff, Coos County ASCS, pers. comm., 1986), a long-term solution to the protection of key habitats is a complicated proposition. 
Most of the land that harriers utilize is privately owned; therefore, education of landowners is crucial. At nest sites which have been used for two or more years, landowners should be notified of the presence of harrier nests, and members of the Endangered Species Program should request their cooperation in preventing disturbance. I found that landowners in the area were happy to cooperate with my study efforts, and in many cases were interested in the biology and preservation of these birds.

Secondly, if feasible, the maintenance of breeding habitats could be assured through landowner agreements. Early successional stages could be maintained through prescribed burning and grazing, which has been recommended by Duebbert and Lokomoen (1977), Kirsch et al. (1978), and Hamerstrom (1986). In other regions where harriers breed in disturbed habitats, such as drained marshes and farming areas, these raptors have continued to breed, provided that nesting habitats were plentiful and an adequate prey base was available (Hamerstrom 1979; Hamerstrom et al. 1986; Simmons et al. $1986 \mathrm{~b})$.

The threats to breeding harriers from human activity at the study area have thus far remained minimal. Harriers were not disturbed by the activities of dairy farmers; the birds often nested adjacent to hayfields and pastures. Nests built in hayfields could be destroyed by mowing, which occurs between early July and September. Although at least one harrier nest was found in a hayfield (D. Killam, pers. comm., 1985), no other reports have been received 
since the monitoring program began.

Timber cutting may affect breeding harriers both negatively and positively. Logging provides hunting and breeding habitats. Harriers were observed hunting over and nesting in or near logged areas. Negative effects from logging include disturbance from machinery if cutting occurred adjacent to a nest site, especially during the nest building and incubation stages, when harriers are most vulnerable (Hamerstrom 1969).

Buffer zones around nest sites have been recommended for the protection of threatened raptor species in other studies (Bednarz and Dinsmore 1981; White and Thurow 1985). Buffer zones around harrier nests would prevent disturbance from logging activities, off-road vehicle use and other detrimental human activities. Studies on buffer zones for harrier nests have not been published. Although an arbitrary cut-off zone may be helpful, the response to disturbance by breeding harriers varies individually (Schipper 1973; P. Serrentino, pers. obs.). In Alaska, the buffer zones around raptor nests varied from $3.22 \mathrm{~km}$ in diameter for Peregrine Falcons to $0.8 \mathrm{~km}$ for Rough-legged Hawks (Olendorff and Kochert 1977).

The monitoring program begun by the Endangered Species Program should continue, and be expanded if possible. The minimum amount of information which should be collected annually is the number of harrier nests (including failed nests if possible) and the number of fledglings produced 
per nest. At the present time the entire study area is not surveyed for breeders. Fledgling counts are conducted once during the summer, on Harrier Day, with the result that some sites are missed and accurate counts of fledglings from nests may be impossible. Information collected during 1984 and 1985 indicates that harriers fledge at the study area from the end of July until mid-August. During the fledging period, frequent checks of known nest sites and potential breeding habitat in areas which have not been surveyed extensively would improve the accuracy of density estimates and fledgling production.

The above program could also be implemented in New England by both private and state environmental agencies. Biologists should continue to monitor known breeding sites, protect key habitats from development and detrimental human disturbance, and investigate new areas with suitable breeding habitats for evidence of previously unreported populations. Because of the harrier's ground-nesting habits, it is difficult to locate nests. The best strategy for monitoring harriers may be intensive investigation of nesting habitats throughout July and August, when the birds have fledged and remain at the nest sites for two to four weeks (Hamerstrom 1969; Watson 1977).

The relationship between maintenance of harrier populations in farming areas and the type of agricultural practices (such as the proportion of the area used for crops vs hayfields and pastures, and the frequency with which hay fields are mowed during the growing season) which 
they tolerate needs further research. Harriers have bred in agricultural areas in New Brunswick (Simmons et al. 1986b), Michigan (Craighead and Craighead 1956), and the Netherlands (Schipper 1973). In similar regions throughout New England, harriers either do not breed in high numbers (Tom French, Massachusetts Natural Heritage Program, pers. comm., 1987), or these areas have not been sufficiently surveyed for birds. In upstate New York (M. England, Long Island University, pers. comm., 1987), harriers are uncommon in farming areas.

Harriers may not breed in other farming areas in New England because of several factors: crops, such as corn, are more frequently grown; hayfields are cut more often; and breeding habitats may be unavailable. Extensive croplands and several hay cuttings may depress populations of small mammals by reducing cover (Birney et al. 1976; Baker and Brooks 1981; Gilmer and Stewart 1983). Ferruginous hawks in North Dakota (Gilmer and Stewart 1983) maintained the highest nest densities in areas where less than $50 \%$ of the agricultural land was under cultivation. In coos County, crops are rarely grown because of the cool, short summers (J. Aimey, pers. Comm., 1985). Hayfields and grazed cow pastures are the principal open habitats maintained by dairy farmers. Hayfields are cut only once during the summer, as opposed to farming practices in more southern areas (P. Serrentino, pers. obs.). old fields, the result of abandoned farms from previous years, and 
logged areas provide breeding habitat for harriers.

The population of breeding harriers in coos county is tied to the open habitats created by the dairy farming industry. Because of the destruction and degradation of traditional breeding habitats (salt- and freshwater wetlands in New England), agricultural areas assume even greater importance. The management and preservation of open habitats will help insure that the Northern Harrier remains a breeding species in New England. 


\section{APPENDIX A: Natural History of Northern Harriers}

The Northern Harrier (Circus cyaneus) is the only

North American representative of the genus Circus (American Ornithologists' Union 1983). Nine or ten species of harriers are recognized by various authorities. The Northern Harrier occurs throughout Europe and Asia as the Hen Harrier (C. cyaneus cyaneus), a different race from the Northern Harrier (Watson 1977).

Harriers are slim, long-tailed and long-legged hawks which often hunt close to the ground, over open habitats. The male and female harrier are sexually dimorphic with respect to size and color. The female is larger than the male. She is dark brown above and buffy below, whereas the male is pale grey above and white below. Adult and immature birds of both sexes have a distinctive white rump patch. Immatures are similar in color to the female, but have cinnamon-colored, streaked breasts (Bent 1937; Watson 1977; Terres 1980).

The courtship flight of the Northern Harrier consists of a series of conspicuous, U-shaped dives, which frequently occur above the nesting grounds. This display is usually performed by the male only (Breckenridge 1935; Bent 1937; Watson 1977).

Northern Harriers nest on the ground, in a variety of habitats such as salt marshes, sphagnum bogs, shrubdominated swamps and slopes, and wet, grassy hollows (Urner 1925; Bent 1937). Eggs are laid from March to July. 
Incubation is performed by the female and takes approximately 31 to 32 days; the young fledge at 30 to 35 days after hatching (Hamerstrom 1969). During the nesting cycle, the female is supplied with food by the male. This is accomplished by a prey exchange, in which the male flies over the nest site and passes prey to the female while both are in mid-air (Breckenridge 1935; Hecht 1951).

The Northern Harrier nests solitarily, or in loose colonies in which polygyny may occur (Breckenridge 1935; Hecht 1951; Hamerstrom 1969; Clark 1972; Balfour and Cadbury 1979). During winter, harriers form communal roosting flocks (Bent 1937; Watson 1977).

The Northern Harrier winters as far north as southern Canada, along the coast of southern New England, and as far south as Cuba. It breeds from Alaska south to California, Texas and Virginia (Heintzelman 1979; Terres 1980). 
GRASSES AND FORBS:

Dactylis glomerata**

Eupatorium maculatum

Epilobium angustifolium

Solidago spp.

SHRUBS :

Spiraea latifolia

Cornus stolonifera

Rubus idaeus

Salix spp.
Orchard Grass

Spotted Joe-Pyeweed

Fireweed

Goldenrod

Meadowsweet

Red-Osier Dogwood

Red Raspberry

Willow

** Sources of scientific names: Brown 1979; Dwelley 1980; Peterson and McKenney 1968. 


\section{APPENDIX C}

\section{old Field Vegetation Analysis}

Six old fields of different successional stage were investigated to determine if hunting harriers preferred particular types of old fields, possibly because of differences in small mammal abundance and/or in vegetation cover. Because I had few observations of harriers hunting in these habitats in 1984 and 1985, the relationship between small mammal abundance, vegetation structure and use of old fields remains unknown. The results of the vegetation analysis are discussed here to show the techniques used. Small mammals were trapped on four out of the six old fields which were used for vegetation sampling (Field 1, Foss; Field 2, Bushwack; Field 4, Shrew; Field 5, Access). The six fields were located in areas containing breeding pairs or where harriers were observed hunting.

\section{Methods}

The fields were first characterized qualitatively by the amount of woody and grass cover present: old field, early successional stage (plant cover primarily grasses and forbs, little woody vegetation), or late successional stage (grasses and forbs still present, but woody vegetation common). These fields were then sampled to determine if differences among fields occurred with respect to the following parameters: 1) percent cover of grasses, forbs and woody plants less than 1 meter in height, and 2) species composition, relative frequency and relative 
density of woody plants greater than 1 meter in height. old fields were analyzed using the point-centered quarter method (Cottam et al. 1953; Mueller-Dombois and Ellenberg 1974) and the quadrat-charting method (MuellerDombois and Ellenberg 1974). A diagonal transect line was laid across each field; the line was divided into ten sampling points. Vegetation was sampled at a randomly chosen point between each pair of points.

The fraction of plant cover, and the species, frequency and density of woody plants more than $1 \mathrm{~m}$ was determined with the point-centered quarter method. At each sampling point four quarters were laid out, forming a cross equivalent to the four cardinal directions. The distance from the midpoint of the nearest woody shrub or sapling to each quarter was measured. In addition, species and diameter at breast height and/or crown diameter were also recorded.

The percent cover of grasses, herbaceous forbs and shrubs less than $1 \mathrm{~m}$ tall in each field was calculated using the quadrat-charting method. At the same sampling point, a one meter-squared quadrat was placed over the vegetation and the fraction of each type of plant cover estimated.

\section{Vegetation Composition of old Fields}

A one-way ANOVA (Table Cl) was performed on the results of the quadrat-charting method to determine if there was a significant difference among any of the six 
TABLE Cl: Differences among cover types (ANOVA) of six old fields in coos county.

\begin{tabular}{lll} 
Cover Type & F Value & Probablil \\
\hline Grass & 5.954 & $\mathrm{P}<0.001$ \\
Forbs & 3.593 & $\mathrm{P}<0.01$ \\
Woody Vegetation & 2.636 & $\mathrm{P}<0.05$ \\
Dead Vegetation & 3.328 & $\mathrm{P}<0.05$ \\
Moss & 1.292 & $\mathrm{P}>0.05$
\end{tabular}


fields sampled (three early successional fields, numbers one, three and five; three late successional fields, numbers two, four and six) with respect to percent cover of grasses, forbs, woody vegetation, dead vegetation and moss. Percent cover values were arcsine transformed to convert to mean values for analysis. Highly significant differences among fields with respect to percent cover of grasses ( $p<$ $.001)$ and forbs $(p<.01)$ were found. Woody and dead cover were also significantly different among fields ( $p<.05)$. Percent cover of moss did not differ among fields ( $p$ > $.05)$.

If a significant difference $(p<.05)$ in percent cover among any fields was indicated from the ANOVA, a Tukey's wprocedure (Steel and Torrie 1960) was used on the means for each cover value to determine which fields differed from each other with respect to grass, forbs, woody vegetation and dead cover. Moss was not analyzed because significant differences among fields were not found for this cover type. The results of Tukey's test are contained in Table $\mathrm{C} 2$.

Field number 6 (late successional stage) had significantly less grass cover than fields 3 or 5 (both early successional stage), and field number 4 (late successional stage) had significantly less grass cover than field 5. Field 5 had significantly less forb cover than fields 1 (early successional stage), 2 (late successional stage) and 6 . With respect to woody vegetation, there were 
TABLE C2: Tukey's Test: Mean cover values from the one-way ANOVA performed on the six old fields.

Cover Type

GRASS FORBS

WOODY

DEAD

$$
\mid \begin{array}{ll}
.085 & (5) \\
.290 & (3) \\
.330 & (4) \\
.354 & (1) \\
.365 & (2) \\
.387 & (6)
\end{array}
$$

(3)

The mean values joined by the vertical lines are not signficantly different from each other.

The cover type, moss, was omitted because differences in cover values among old fields were not significant.

* Field number in parentheses.

Fields 1,3 and 5 were early successional fields; fields 2, 4 and 6 were late successional fields. Fields 1, 2, 4 and 5 were censused for small mammal abundance (Table 15). 
no significant differences among any fields from the results of Tukey's test, although the results of the ANOVA indicated a significant difference $(p<.05)$. It appeared that the differences in woody cover among fields were too close to be detected by Tukey's test.

Importance values or IV's (Cottam and Curtis 1956; Mueller-Dombois and Ellenberg 1974) were calculated for all species of woody plants greater than $1 \mathrm{~m}$ in height in the six fields sampled by the point-centered quarter method. These values were determined by summing the relative density and relative frequency of each species. Species with the highest IV's in a field were considered the most "important" species, with respect to frequency and density. The plant species with the highest IV's were fairly similar among fields, regardless of whether the field was labeled early or late successional stage (Table C3). Species with high IV's (greater than 25) in early successional fields were meadowsweet (S. latifolia), apple (P. malus), chokecherry (P. virginiana), white spruce (P. glauca) and black willow (s. nigra). Species with high IV's in late successional fields were bebb (S. bebbiana) and black willow, chokecherry and meadowsweet. Meadowsweet had the highest IVs' in four out of six of the fields.

The differences among fields with respect to the number of species (for woody vegetation greater than one $m$ tall) in early and late successional stages were again slight. Early successional stages had from 5 to 10 species present, and late successional stages from 7 to 12 species. 

TABLE C3: The importance values of plant species in six old
fields

old Field

Successional

Stage:

Early

Late

Field Number:

$\overline{\text { One Three Five }}$

Two Four six

Plant Species:

\begin{tabular}{|c|c|c|c|c|c|c|}
\hline Abies balsamea & 0.0 & 12.1 & 0.0 & 5.9 & 0.0 & 0.0 \\
\hline Larix laricina & 6.7 & 0.0 & 0.0 & 0.0 & 0.0 & 0.0 \\
\hline Picea rubens & 0.0 & 18.2 & 0.0 & 0.0 & 0.0 & 0.0 \\
\hline Picea glauca & 13.3 & 31.8 & 0.0 & 11.9 & 0.0 & 15.2 \\
\hline Salix bebbiana & 13.3 & 8.6 & 7.5 & 43.2 & 43.3 & 6.3 \\
\hline Salix nigra & 0.0 & 50.0 & 0.0 & 37.2 & 40.8 & 6.3 \\
\hline Populus tremuloides & 0.0 & 0.0 & 0.0 & 5.9 & 0.0 & 6.3 \\
\hline Betula populifolia & 0.0 & 6.1 & 0.0 & 5.9 & 0.0 & 0.0 \\
\hline Alnus rugosa & 0.0 & 0.0 & 0.0 & 11.9 & 0.0 & 12.7 \\
\hline Fagus grandifolia & 0.0 & 0.0 & 0.0 & 0.0 & 6.7 & 0.0 \\
\hline Spiraea latifolia & 70.8 & 48.9 & 112.5 & 14.4 & 55.0 & 65.8 \\
\hline Pyrus malus & 34.2 & 0.0 & 45.0 & 5.9 & 22.5 & 17.7 \\
\hline Prunus serotina & 0.0 & 0.0 & 7.5 & 14.4 & 6.7 & 0.0 \\
\hline Prunus virginiana & 61.7 & 6.1 & 27.5 & 34.7 & 25.0 & 63.3 \\
\hline Rubus idaeus & 0.0 & 6.1 & 0.0 & 8.4 & 0.0 & 0.0 \\
\hline Cornus stolonifera & 0.0 & 12.1 & 0.0 & 0.0 & 0.0 & 0.0 \\
\hline Viburnum trilobum & 0.0 & 0.0 & 0.0 & 0.0 & 0.0 & 6.3 \\
\hline $\begin{array}{l}\text { Sum of } \\
\text { Importance } \\
\text { Values }\end{array}$ & 200.0 & 200.0 & 200.0 & 199.7 & 200.0 & 199.9 \\
\hline
\end{tabular}




\section{Discussion}

The data collected on percent cover of vegetation less than $1 \mathrm{~m}$ in height suggested that the primary differences between early and late successional fields were in the amount of grass cover present. Although these fields also differed with respect to woody, forb and dead cover, these differences were not related to the successional stage of the field (e.g., early or late successional stage). For vegetation greater than one meter in height, the species with the highest IV's in both early and late successional fields were often similar, in addition to the number of species present. I conclude that the primary difference between early and late successional fields at the study area was in the amount of grass cover present. 


\section{APPENDIX D: Scientific and Common Names of Plant Species}

Found in old Fields

FAMILY: PINACEAE

Abies balsamea**

Larix laricina

Picea rubens

Picea glauca

FAMILY: SALICACEAE

Salix bebbiana

Salix nigra

Populus tremuloides

FAMILY: CORYLACEAE

Betula populifolia

Alnus rugosa

FAMILY: FAGACEAE

Fagus grandifolia

FAMILY: ROSACEAE

Spiraea latifolia

Pyrus malus

Prunus serotina

Prunus virginiana

$\underline{\text { Rubus }}$ idaeus

FAMILY : CORNACEAE

Cornus stolonifera

FAMILY : CAPRIFOLIACEAE

Viburnum trilobum
Balsam Fir

American Larch

Red Spruce

White Spruce

Bebb or Beaked Willow

Black Willow

Trembling Aspen

Gray Birch

Speckled Alder

American Beech

Meadowsweet Common Apple wild Black Cherry

Choke Cherry

Red Raspberry

Red-Osier Dogwood

** Source of scientific names: Dwelley 1980. 


\section{APPENDIX E}

Table El: The total amount of time (in seconds) that harriers were observed; for analysis of habitat selection.

YEAR BREEDING STATUS SEX NO. BIRDS DURATION

(in seconds, and percent of totall

1984 a. breeders

$\begin{array}{lll}\text { female } & 3 & 4291 \\ \text { male } & 2 & 1301\end{array}$

Total: 5592

b. unknown*

female

1

531 (88)

male

2

71 ( 12$)$

Total: 602

1985

a. breeders

female

4

1712 (92)

male

2

158

(8)

Total: 1870

b. unknown*

female

4

415 (26)

male

6

1192 (74)

Total: 1607 
Table El continued.

YEAR BREEDING STATUS SEX

NO. BIRDS DURATION

(in seconds, and percent of total)

$1984 / 1985$

Total: a. breeders

female

male

b. unknown*

c. all birds

female

male

female

male

5

8

1263 (57)

Total: 2209

Total: 7462

1459 (20)

Total: 7462

$946 \quad(43)$

8

6949 (72)

12

2722 (28)

Grand Total: 9671

* The category of unknown birds represents the minimum number of individuals sampled. Because the birds were not marked, the number of unknown birds is considered an estimate. 
Table E2: The total amount of time (in seconds) that harriers were observed, for analysis of hunting behavior.

YEAR BREEDING STATUS SEX

NO. BIRDS DURATION

(in seconds, and percent of total)

1984 a. breeders

female

3

$3819(76)$

male

2

1217 (24)

Total: 5036

b. unknown *

female

1

$214(100)$

male

0

0

(0)

Total: 214

1985 a. breeders

female

4

$1888 \quad(94)$

male

2

119

(6)

Total: 2007

b. unknown*

female

4

538 (32)

male

4

1149 (68)

Total: 1687 
Table E2 continued.

\begin{tabular}{ccc} 
YEAR BREEDING STATUS SEX NO. BIRDS & $\begin{array}{c}\text { DURATION } \\
\text { (in seconds, } \\
\text { and percent } \\
\text { of total) }\end{array}$ \\
\hline
\end{tabular}

$1984 / 1985$

Total: a. breeders

female

male

b. unknown*

c. all birds female

male

male female
7

5707

1336

4

Total: 7043

5

$752(40)$

4

$1149 \quad(60)$

Total: 1901

12

6459 (72)

8

2485

(28)

Grand Total: 8944

The category of unknown birds represents the minimum number of individuals sampled. Because the birds were not marked, the number of unknown birds is considered an estimate. 
Table E3: The total amount of time (in seconds) that harriers were observed, for analysis of flight altitude.

YEAR BREEDING STATUS SEX

NO. BIRDS
DURATION
(in seconds, and percent of total)

1984 a. breeders

female

male

b. unknown * female

male
1

2
$3646 \quad(75)$

1199 (25)

Total: 4845

Total: 460

1985 a. breeders

female

male 2

4

1851 (93)

134

Total: 1985

b. unknown * female

male
4

7
534 (31)

1195 (69)

Total: 1729 
Table E3: continued.

\begin{tabular}{ll} 
YEAR BREEDING STATUS SEX NO. BIRDS & $\begin{array}{l}\text { DURATION } \\
\text { (in seconds, } \\
\text { and percent } \\
\text { of total) }\end{array}$ \\
\hline
\end{tabular}

$1984 / 1985$

Total: a. breeders

$\begin{array}{llrl}\text { female } & 7 & 5497 & (80) \\ \text { male } & 4 & 1333 & (20) \\ & & \text { Total: } & 6830\end{array}$

b. unknown*

female

5

$923 \quad(42)$

male

9

$1266 \quad(58)$

Total $: 2189$

c. all birds

female

12

6420

(71)

male

13

2599

Grand Total : 9019

* The category of unknown birds represents the minimum number of individuals sampled. Because the birds were not marked, the number of unknown birds is considered an estimate. 


\section{APPENDIX F}

TABLE Fl: Raw Data For Habitat Selection; observation time in seconds. Explanations of abbreviations for habitats and identification of birds (e.g., DP) are found in Table F4.

\begin{tabular}{|c|c|c|c|c|c|c|}
\hline & & & ITAT & $\mathrm{PE}$ & & \\
\hline $\begin{array}{l}\text { Known birds } \\
\text { (breeders) } \\
1984\end{array}$ & $\mathrm{HAY}$ & FOR & EDG & SHR & PAS & Total \\
\hline DP female & 639 & 0 & 80 & 215 & 0 & 934 \\
\hline DP male & 260 & 35 & 95 & 0 & 0 & 390 \\
\hline FH female & 930 & 1331 & 502 & 570 & 0 & 3333 \\
\hline FH male & 129 & 221 & 55 & 506 & 0 & 911 \\
\hline GL female & 0 & 0 & 0 & 24 & 0 & 24 \\
\hline Total & 1958 & 1587 & 732 & 1315 & 0 & 5592 \\
\hline \multicolumn{7}{|l|}{$\begin{array}{l}\text { Known birds } \\
1985\end{array}$} \\
\hline DP female & 28 & 0 & 0 & 0 & 0 & 28 \\
\hline FH female & 191 & 633 & 111 & 311 & 0 & 1246 \\
\hline $\mathrm{FH}$ male & 0 & 62 & 16 & 30 & 0 & 108 \\
\hline MM female & 0 & 56 & 17 & 0 & 271 & 344 \\
\hline MM male & 0 & 26 & 24 & 0 & 0 & 50 \\
\hline AL female & 0 & 8 & 0 & 86 & 0 & 94 \\
\hline Total & 219 & 785 & 168 & 427 & 271 & 1870 \\
\hline
\end{tabular}

Unknown birds

1984

\begin{tabular}{lrrrrrr} 
WS male & 28 & 0 & 0 & 0 & 0 & 28 \\
FH male & 43 & 0 & 0 & 0 & 0 & 43 \\
GL female & 468 & 0 & 63 & 0 & 0 & 531 \\
Total & 539 & 0 & 63 & 0 & 0 & 602 \\
\hline
\end{tabular}


Table Fl continued.

Unknown birds HAY FOR $\quad$ EDG $\quad$ SHR PAS Total

\section{5}

GL male

GL male

PE male

FS male

FS female

FR male

FR male

AF female

RN female

RN male

DP male

GG female

MM male

$\mathrm{NH}$ female

$\mathrm{NH}$ male

NH male

$\mathrm{NH}$ male

$\mathrm{NH}$ male

NH male

Total

Total All

Birds
43

163

49

72

0

16

38

0

0

0

0

25

77

0

29

21

69

30

24

656

$3372 \quad 2958$

347

586
41

0

0

0

18

0

0

0

10

41

45

39

7

62

19

0

12

0
6

300

36

1263

1778

300

9671
84

163

49

72

18

16

38

171

23

57

45

64

84

139

48

21

108

30

377

1607
2

.


Table F2: Raw Data For Hunting Behavior; observation time in seconds. Explanations of abbreviations for behaviors and identification of birds (e.g., DP) are found in Table F4.

\section{BEHAVIOR}

Known birds CIR DBT TRN GDV QUR HVF DIP BFL Total (breeders)

1984

$\begin{array}{llrrrrrrrrr}\text { DP } & \text { female } & 325 & 20 & 95 & 14 & 0 & 246 & 107 & 26 & 833 \\ \text { DP } & \text { male } & 14 & 0 & 173 & 0 & 0 & 0 & 108 & 110 & 405 \\ \text { FH female } & 1015 & 222 & 896 & 23 & 0 & 215 & 188 & 403 & 2962 \\ \text { FH male } & 126 & 530 & 65 & 0 & 0 & 0 & 36 & 55 & 812 \\ \text { Total } & 1480 & 772 & 1229 & 37 & 0 & 461 & 439 & 594 & 5012\end{array}$

Known birds

1985

\begin{tabular}{|c|c|c|c|c|c|c|c|c|c|}
\hline female & 0 & 0 & 28 & 0 & 0 & 0 & 0 & 0 & 28 \\
\hline female & 768 & 49 & 134 & 0 & 0 & 445 & 0 & 111 & 1507 \\
\hline male & 23 & 0 & 30 & 0 & 0 & 0 & 0 & 16 & 69 \\
\hline female & 105 & 0 & 8 & 0 & 0 & 179 & 36 & 17 & 345 \\
\hline male & 0 & 26 & 0 & 0 & 0 & 0 & 24 & 0 & 50 \\
\hline female & 0 & 0 & 8 & 0 & 0 & 0 & 0 & 0 & 8 \\
\hline otal & 896 & 75 & 208 & 0 & 0 & 624 & 60 & 144 & 2007 \\
\hline
\end{tabular}

Unknown birds

1984

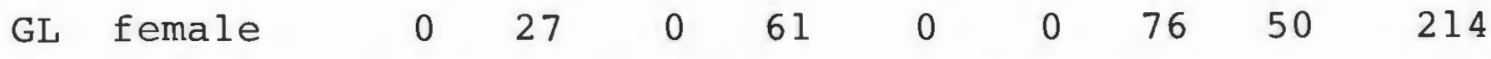


Table F2 continued.

Unknown birds CIR DBT TRN GDV QUR HVF DIP BFI Total 1985

\begin{tabular}{|c|c|c|c|c|c|c|c|c|c|c|}
\hline GL & male & 0 & 0 & 43 & 0 & 0 & 0 & 0 & 41 & 84 \\
\hline GL & male & 0 & 0 & 125 & 0 & 0 & 38 & 0 & 0 & 163 \\
\hline $\mathrm{GL}$ & male & 0 & 0 & 0 & 0 & 0 & 44 & 0 & 0 & 44 \\
\hline FS & male & 0 & 0 & 52 & 0 & 20 & 0 & 0 & 0 & 72 \\
\hline FS & female & 0 & 0 & 0 & 0 & 0 & 0 & 11 & 18 & 29 \\
\hline $\mathrm{FH}$ & male & 0 & 0 & 16 & 0 & 0 & 0 & 0 & 0 & 16 \\
\hline $\mathrm{FH}$ & male & 0 & 0 & 27 & 0 & 7 & 0 & 0 & 0 & 34 \\
\hline $\mathrm{AF}$ & female & 192 & 0 & 75 & 0 & 0 & 29 & 0 & 0 & 296 \\
\hline RN & female & 0 & 0 & 0 & 0 & 0 & 0 & 0 & 10 & 10 \\
\hline RN & male & 0 & 0 & 16 & 0 & 0 & 0 & 0 & 41 & 57 \\
\hline GG & female & 0 & 0 & 25 & 0 & 0 & 0 & 0 & 39 & 64 \\
\hline MM & male & 0 & 0 & 31 & 0 & 0 & 46 & 0 & 7 & 84 \\
\hline $\mathrm{NH}$ & female & 51 & 14 & 54 & 0 & 0 & 0 & 0 & 20 & 139 \\
\hline $\mathrm{NH}$ & male & 0 & 0 & 0 & 0 & 16 & 0 & 13 & 19 & 48 \\
\hline $\mathrm{NH}$ & male & 0 & 0 & 21 & 0 & 0 & 0 & 0 & 0 & 21 \\
\hline $\mathrm{NH}$ & male & 36 & 0 & 60 & 0 & 0 & 0 & 0 & 12 & 108 \\
\hline $\mathrm{NH}$ & male & 0 & 0 & 30 & 0 & 0 & 0 & 0 & 0 & 30 \\
\hline $\mathrm{NH}$ & male & 49 & 262 & 77 & 0 & 0 & 0 & 0 & 0 & 388 \\
\hline \multicolumn{2}{|c|}{ Total } & 328 & 276 & 652 & 0 & 36 & 157 & 24 & 207 & 1680 \\
\hline $\begin{array}{l}\text { Tota } \\
\text { Bird }\end{array}$ & $\begin{array}{ll}1 & A \\
\text { a } & \end{array}$ & 2704 & 1150 & 2089 & 98 & 36 & 1242 & 599 & 995 & 8913 \\
\hline
\end{tabular}


Table F3: Raw Data For Flight Altitude; observation time in seconds. Explanations of abbreviations for heights and identification of birds (e.g., DP) are found in Table F4.

HEIGHTS

Known birds LOW MED TRE ABT L/M M/T TTA Total (breeders)

1984

\begin{tabular}{|c|c|c|c|c|c|c|c|c|c|}
\hline $\mathrm{DP}$ & female & 70 & 30 & 116 & 260 & 101 & 37 & 23 & 637 \\
\hline DP & male & 123 & 72 & 26 & 21 & 96 & 0 & 0 & 338 \\
\hline $\mathrm{FH}$ & female & 293 & 445 & 1080 & 414 & 522 & 107 & 124 & 2985 \\
\hline $\mathrm{FH}$ & male & 42 & 75 & 593 & 96 & 0 & 36 & 19 & 861 \\
\hline GL & female & 0 & 0 & 0 & 0 & 0 & 0 & 24 & 2 \\
\hline
\end{tabular}

Total

528

$622 \quad 1815 \quad 791$

$719 \quad 180 \quad 190$

4845

Known birds

1985

$\begin{array}{llrrrrrrrr}\text { DP } & \text { female } & 0 & 28 & 0 & 0 & 0 & 0 & 0 & 28 \\ \text { FH } & \text { female } & 0 & 110 & 392 & 675 & 0 & 21 & 287 & 1485 \\ \text { FH male } & 0 & 46 & 62 & 0 & 0 & 0 & 0 & 108 \\ \text { MM female } & 17 & 8 & 39 & 66 & 114 & 0 & 0 & 244 \\ \text { MM male } & 0 & 0 & 0 & 0 & 0 & 0 & 26 & 26 \\ \text { AL female } & 0 & 0 & 8 & 86 & 0 & 0 & 0 & 94 \\ \text { Total } & 17 & 192 & 501 & 827 & 114 & 21 & 313 & 1985 \\ \end{array}$

Unknown birds

1984

\begin{tabular}{lrrrrrrrr} 
WS male & 0 & 0 & 0 & 0 & 28 & 0 & 0 & 28 \\
FR male & 0 & 0 & 0 & 0 & 43 & 0 & 0 & 43 \\
GL female & 52 & 337 & 0 & 0 & 0 & 0 & 0 & 389 \\
Total & 52 & 337 & 0 & 0 & 71 & 0 & 0 & 460 \\
\hline
\end{tabular}


Table F3 continued.

LOW MED TRE ABT L/M M/T TTA Total

Unknown birds

1985

\begin{tabular}{|c|c|c|c|c|c|c|c|c|c|}
\hline GL & male & 84 & 0 & 0 & 0 & 0 & 0 & 0 & 84 \\
\hline GL & male & 163 & 0 & 0 & 0 & 0 & 0 & 0 & 163 \\
\hline $\mathrm{PE}$ & male & 0 & 0 & 0 & 0 & 40 & 0 & 0 & 40 \\
\hline FS & male & 72 & 0 & 0 & 0 & 0 & 0 & 0 & 72 \\
\hline FS & female & 29 & 0 & 0 & 0 & 0 & 0 & 0 & 29 \\
\hline FR & male & 7 & 9 & 0 & 0 & 0 & 0 & 0 & 16 \\
\hline FR & male & 12 & 0 & 0 & 0 & 0 & 0 & 0 & 12 \\
\hline DP & male & 0 & 0 & 0 & 0 & 45 & 0 & 0 & 45 \\
\hline $\mathrm{AF}$ & female & 0 & 0 & 169 & 110 & 0 & 0 & 0 & 279 \\
\hline RN & female & 23 & 0 & 0 & 0 & 0 & 0 & 0 & 23 \\
\hline RN & male & 50 & 7 & 0 & 0 & 0 & 0 & 0 & 57 \\
\hline CL & male & 0 & 0 & 0 & 0 & 0 & 0 & 45 & 45 \\
\hline GG & female & 8 & 48 & 8 & 0 & 0 & 0 & 0 & 64 \\
\hline MM & male & 7 & 31 & 0 & 0 & 46 & 0 & 0 & 84 \\
\hline $\mathrm{NH}$ & female & 0 & 0 & 123 & 0 & 0 & 0 & 16 & 139 \\
\hline $\mathrm{NH}$ & male & 8 & 8 & 0 & 0 & 32 & 0 & 0 & 48 \\
\hline $\mathrm{NH}$ & male & 21 & 0 & 0 & 0 & 0 & 0 & 0 & 21 \\
\hline $\mathrm{NH}$ & male & 0 & 0 & 72 & 36 & 0 & 0 & 0 & 108 \\
\hline $\mathrm{NH}$ & male & 0 & 0 & 30 & 0 & 0 & 0 & 0 & 30 \\
\hline $\mathrm{NH}$ & male & 24 & 0 & 315 & 31 & 0 & 0 & 0 & 370 \\
\hline \multicolumn{2}{|c|}{ Total } & 508 & 103 & 717 & 177 & 163 & 0 & 61 & 172 \\
\hline
\end{tabular}

$\begin{array}{llllllllll}\text { Total All } & 1105 & 1254 & 3033 & 1795 & 1067 & 201 & 564 & 9019\end{array}$ Birds 
TABLE F4: Explanations of abbreviations and identification of birds used in tables Fl through F3.

Explanation of Bird Identification: The abbreviations listed below refer to the locality in which a particular bird was observed.

DP: Diamond Pond

$\mathrm{FH}$ : Forbes Hill

GL: Gould

MM: Mudget Mountain

AL: Alex

AF: Alfo

WS: West

FS: Foss

FR: Forbes/Reed

RN: Rainville

GG: Guigere

$\mathrm{NH}$ : North Hill

PE: Perry

CL: Clark

Habitat Abbreviations:

HAY: hayfield

FOR: forest

EDG: edge habitats

SHR: shrub habitats (includes logged areas, shrub wetlands and old fields)

PAS: pasture

Behavior Abbreviations:

CIR: circling

DBT: diving between trees

TRN: transect

GDV: ground hunt

QUR: quartering

HVF: hover-flying

DIP: dipping

BFL: border following 
Table F4 continued.

Flight Altitude Abbreviations:

LOW: low

MED : medium

TRE : tree-top

ABT: above-trees

L/M: low/medium

M/T: medium/tree-top

TTA: tree-top/above-trees 
APPENDIX G: Scientific and Common Names of Mammal Species Trapped at the Study Area in 1985

FAMILY SORICIDAE

Blarina brevicauda**

Shorttail Shrew

FAMILY TALPIDAE

Condylura cristata

Starnose Mole

FAMILY CRICETIDAE

Peromyscus maniculatus

or leucopus

Deer or White-footed Mouse

Clethrionomys gapperi

Boreal Redback Vole

Microtus pennsylvanicus

Meadow Vole

FAMILY ZAPODIDAE

Zapus hudsonius

Meadow Jumping Mouse

Napaeozapus insignis

Woodland Jumping

Mouse

** Source of scientific names: Burt and Grossenheider 1976. 


\section{APPENDIX H}

TABLE Hl: Prey remains and pellets found at the Reed/Alex nest site, 1985 .

1. Small Rodent (all)

(long bones, incisors,

foot bones, claws)

2. Subfamily Microtinae

(teeth, jaw fragments

with teeth)

3. Microtus spp.

(jaw fragments with teeth)

3. Bird

(beak, feet, skin, claws)

4. Snake

(vertebrae, scales)

B. Pellet Fragment Contents: small rodent, subfamily Microtinae, Microtus spp., bird, snake, unidentified bone fragments.

c. Prey Remains: Keels from small- and medium-sized birds, unidentified feathers from small birds, pectoral girdle from medium-sized bird, Common Flicker (Colaptes auratus), young Eastern garter snakes (Thamnophis sirtalis).

D. Primary Constituents of Pellets: 6 contained > 50\% fur, 1 contained $>50 \%$ feathers, 1 contained approximately $50 \%$ fur and 50\% feathers, 1 contained approximately 50\% fur and $50 \%$ snake scales. 
TABLE H2: Prey remains and pellets found at the Mudget Mountain nest site, 1985.

Number of Intact Pellets (7)

1. Small Rodent (al1) 5

2. Subfamily Microtinae 2

3. Zapus hudsonius (upper jaw with teeth)

4. Bird

5. Snake

6. Unidentified bone 2 fragments

B. Pellet Fragment Contents: small rodent, subfamily Microtinae, small bird.

C. Prey Remains: feathers from small bird.

D. Primary Constituents of Pellets: 3 contained > 50\% fur, 2 contained > 50\% feathers, 2 contained approximately $50 \%$ fur and $50 \%$ feathers. 
TABLE H3: Prey remains and pellets found at the Forbes Hill nest site, 1985.

Number of Intact Pellets (18)

1. Small rodent (all)

2. Subfamily Microtinae

3. Microtus spp.

4. Blarina brevicauda

5. Bird

6. Snake

B. Pellet Fragment Contents: Small rodent, Subfamily Microtinae, Blarina brevicauda, bird, snake, unidentified bone fragments.

C. Prey Remains: Adult Tamiasciurus hudsonicus, keels from medium-sized birds, feathers from medium-sized bird, feathers from adult American Robin (Turdus migratorius).

D. Primary Constituents of Pellets: 13 contained > 50\% fur, 2 contained > 50\% feathers, 1 contained > 50\% snake, 1 contained approximately 50\% fur and 50\% plant material, 1 contained approximately $50 \%$ feathers and $50 \%$ plant material. 
TABLE H4: Prey remains and pellets found at the Diamond Pond nest site, 1985.

Number of Intact Pellets (18)

1. Small rodent (all)

2. Family Zapodidae

3. Subfamily Microtinae

4. Microtus spp.

5. Tamias striatus

(jaw with teeth)

6. Blarina brevicauda

7. Bird

8. Order Passeriformes (beak)

9. Snake

10. Unidentified bone fragments

B. Pellet Fragment Contents: Small rodent, Family Zapodidae, Zapus hudsonius, subfamily Microtinae, Microtus spp., Microtus pennsylvanicus, Blarina brevicauda, bird, snake, unidentified bone fragments.

C. Prey Remains: Young Tamiasciurus hudsonicus, feathers from unidentified birds, feathers from full-grown Common Flicker and Ruffed Grouse (Bonasa umbellus), feathers from young Ruffed Grouse, partial skeleton and feathers from small passerine; feet, legs and synsacrum from medium-sized passerine, keels and beak from small birds, synsacrum from medium-sized bird, pectoral girdle of small passerine, skull and beak of full-grown Bobolink (Dolichonyx oryzivorus), skin and scales from snake.

D. Primary Constituents of Pellets: 10 contained $>50 \%$ fur, 4 contained approximately $50 \%$ fur and $50 \%$ feathers, 3 contained > 50\% feathers, 1 contained > 50\% plant fragments .

Note: most fragments contained varying amounts of insect and plant fragments. 


\section{BIBLIOGRAPHY}

Altmann, J. 1974. Observational study of behavior: sampling methods. Behaviour 49: 227-267.

American Ornithologists' Union. 1983. Check-List of North American Birds, 6th ed. Allen Press, Inc., Lawrence,

Kansas.

Arbib, R. 1973. The Blue List for 1974. Am. Birds 27: 943945 .

Baird, S.F., J. Cassin, and G.N. Lawrence. 1860. The Birds of North America. J.B. Lippincott and Co., Philadelphia, Pennsylvania.

Baird, S.F., T.M. Brewer, and R. Ridgway. 1874. A History of North American Birds, Land Birds. Vol. 3. Little, Brown, and Co., Boston, Massachusetts.

Baker, J.A., and R.J. Brooks. 1981. Distribution patterns of raptors in relation to density of Meadow voles. Condor 83: 42-47.

Baldwin, J.L. 1973. Climates of the United States. United States Dept. of Commerce, National Oceanic and Atmospheric Administration, Washington, D.C.

Balfour, E., and C.J. Cadbury. 1975. A population study of the Hen Harrier, Circus cyaneus in orkney. Pp. 122128 in The Natural Environment of Orkney (R. Goodier, ed.). The Nature Conservancy Council, Edinburgh, Scotland.

- 1979. Polygyny, spacing and sex ratio among Hen Harriers Circus cyaneus in Orkney, Scotland. Ornis scand. 10: 133-141.

Balfour, E., and M.A. MacDonald. 1970. Food and feeding behaviour of the Hen Harrier in Orkney. Scot. Biras 6: 157-166.

Bechard, M.J. 1982. Effect of vegetative cover on foraging site selection by Swainson's Hawk. Condor 84: 153-159.

Bednarz, J.C., and J.J. Dinsmore. 1981. Status, habitat use, and management of Red-Shouldered Hawks in Iowa. J. Wildl. Mgmt. 45:236-24l.

Beissinger, S.R. 1983. Hunting behavior, prey selection, and energetics of snail kites in Guyana: consumer choice by a specialist. Auk 100: 84-92.

Bendire, C.E. 1892. Life Histories of North American Birds. U.S. Natl. Mus. Spec. Bull. 1. Washington, D.C. 
Bent, A.C. 1937. Life Histories of North American Birds of Prey, Vol. 1. U.S. Natl. Mus. Bull. 167. Smithsonian Institute, Washington, D.C.

Bildstein, K.L. 1978. Behavioral ecology of Red-tailed hawks (Buteo jamaicensis), Rough-legged hawks (Buteo lagopus), Northern harriers (Circus cyaneus), American kestrels (Falco sparverius), and other raptorial birds wintering in south central ohio. Ph.D. diss., Ohio state university, columbus, Ohio.

Birney, E.C., W.E. Grant, and D.D. Baird. 1976. Importance of vegetative cover to cycles of Microtus populations. Ecology 57: 1043-1051.

Breckenridge, W.J. 1935. An ecological study of some Minnesota Marsh Hawks. Condor 37: 268-276.

Brown, L. 1979. Grasses, An Identification Guide. Houghton Mifflin Company, Boston, Massachusetts.

Brown, L., and D. Amadon. 1968. Eagles, Hawks, and Falcons ofthe World. McGraw-Hill, New York, New York.

Burt, W.H., and R.P. Grossenheider. 1976. A Field Guide to the Mammals, 3rd ed. Houghton Mifflin Company, Boston, Massachusetts.

Clark, R.J. 1972. Observations of nesting Marsh hawks in Manitoba. Blue Jay 30: 43-48.

Collopy, M.W., and K.L. Bildstein. 1987. Foraging behavior of Northern Harriers wintering in southeastern salt and freshwater marshes. Auk 104: 11-16.

Conover, W.J. 1980. Practical Nonparametric Statistics, 2nd ed. John Wiley and Sons, Inc., New York, New York.

Cory, C.B. 1899. The Birds of Eastern North America, Part II, Land Birds. Alfred Mudge and Son, Boston, Massachusetts.

Cottam, G., J.T. Curtis, and B.W. Hale. 1953. Some sampling characteristics of a population of randomly dispersed individuals. Ecology 34: 741-757.

Cottam, G., and J.T. Curtis. 1956. The use of distance measures in phytosociological sampling. Ecology 37: $451-460$.

Craighead, J.J., and F.C. Craighead, Jr. 1956. Hawks, Owls and Wildlife. Stackpole, Harrisburg, Pennsylvania. 
Dowhan, J.J., and R.J. Craig. 1976. Rare and Endangered Species of connecticut and their Habitats. State Geological and Natural History Survey of Connecticut, Department of Environmental Protection, Report of Investigations, No. 6 .

Duebbert, H.F., and J.T. Lokemoen. 1977. Upland nesting of American bitterns, Marsh hawks, and Short-eared owls. Prairie Nat. 9: 33-40.

Dunne, P. 1984. 1983 Northern Harrier breeding survey in coastal New Jersey. Records of New Jersey Birds 10: 25 .

Dwelley, M.J. 1980. Trees and Shrubs of New England. Down East Books, Camden, Maine.

Eisenberg, J.F., M.A. O'Connell, and P.V. August. 1979. Density, productivity, and distribution of mammals in two Venezuelan habitats. Pp. 187-207 in Vertebrate Ecology in the Northern Neotropics ( $\overline{\mathrm{J.F}}$. Eisenberg, ed.). Smithsonian Institution Press, Washington, D.C.

Environmental Systems Research Institute. 1986. ARC/INFO, Geographic Information Systems. Redlands, California.

Errington, P.L. 1932. Techniques of raptor food habits study. Condor 34: 75-86.

Evans, D.L. 1982. Status reports of twelve raptors. U.S. Fish Wildl. Serv., Spec. Sci. Rept.- Wildl. No. 238: $28-32$.

Forbush, E.H. 1929. Birds of Massachusetts and other New England States, Part 2, Land Birds. Norwood Press, Norwood, Massachusetts.

Frayer, W.E., T.J. Monahan, D.C. Bowden, and F.A. Graybill. 1983. Status and trends of wetlands and deepwater habitats in the conterminous United States, 1950's to 1970 's. Dept. of Forest and wood Sciences, colorado State Univ., Fort Collins, Colorado.

Frieswyk, T.S., and A.M. Malley. 1985. Forest statistics for New Hampshire 1973 and 1983. U.S.D.A. For. Serv., Northeastern Station, Resource Bulletin NE-88.

Fyfe, R.W., and H.I. Armbruster, 1977. Raptor research and management in Canada. Pp. 282-293 in World Conference on Birds of Prey, Report of Proceedings (R.D. Chancellor, ed.). International Council for Bird Preservation, Great Britain. 
Gilmer, D.S., and R.E. Stewart. 1983. Ferruginous hawk populations and habitat use in North Dakota. J. Wildl. Mgmt. 47: 146-157.

Glass, B.P. 1951. A Key to the Skulls of North American Mammals. Burgess Publishing Co., Minneapolis, Minnesota.

Gould, E.M., and C.H. Reidel. 1979. The Yankee Forest. J. For. 77: 558-562.

Grubb, T.G., R.I. Knight, D.M. Rubink, and C.H. Nash. 1983. A five-year comparison of Bald Eagle productivity in Washington and Arizona. Pp. 35-45 in Biology and Management of Bald Eagles and Ospreys. (D.M Bird, chief ed.). Harpell Press, Ste. Anne de Bellevue, Quebec.

Hall, E.R. 1981. The Mammals of North America. Vol. 1 and 2, 2nd. ed. John Wiley and Sons, New York, New York.

Hamerstrom, F. 1969. A harrier population study. Pp. 367383 in Peregrine Falcon Populations: Their Biology and Decline. (J.J. Hickey, ed.). Univ. of Wisconsin Press, Madison, Wisconsin.

- 1979. Effect of prey on predator: voles and harriers. Auk 96: 370-374.

- 1986. Harrier, Hawk of the Marshes.

Smithsonian Institution Press, Washington, DC.

Hamerstrom, F., and M. Kopeny. 1981. Harrier nest-site vegetation. Raptor Res. 15: 86-88.

Hamerstrom, F., F.N. Hamerstrom, and C.J. Burke. 1985. Effect of voles on mating systems in a central Wisconsin population of harriers. Wilson Bull. 97: $332-346$.

Hammond, M.C., and C.J. Henry. 1949. Success of Marsh Hawk nests in North Dakota. Auk 66: 271-274.

Hawes, A.F. 1923. New England forests in retrospect. J. For. 21: 209-224.

Hecht, W.R. 1951. Nesting of the Marsh hawk at Delta, Manitoba. Wilson Bull. 63: 167-176.

Heintzelman, D.S. 1979. A Guide to Hawk watching in North America. The Pennsylvania State University Press, University Park, Pennsylvania. 
Hoffman, R. 1910. A Guide to the Birds of New England and Eastern New York. Houghton Mifflin Co., The Riverside Press, Boston, Massachusetts.

Holt, D.W., and S.M. Melvin. 1986. Population dynamics, habitat use, and management needs of the Short-eared Owl in Massachusetts, Summary of 1985 Research. Natural Heritage Program, Massachusetts Division of Fisheries and Wildlife, Boston, Massachusetts.

Janes, S.W. 1984. Influences of territory composition and interspecific competition on Red-tailed hawk reproductive success. Ecology 65: 862-870.

- 1985. Habitat selection in raptorial birds. Pp 159-188 in Habitat selection in Birds (M.L. Cody ed.). Academic Press, Inc., London, England.

Kenward, R.E. 1982. Goshawk hunting behavior, and range size as a function of food and habitat availability. J. Anim. Ecol. 51: 69-80.

Kirsch, L.M., H.F. Duebbert, and A.D. Kruse. 1978. Grazing and haying effects on habitats of upland nesting birds. Trans. N. Am. Wildl. Nat. Resource Conf. 43: 486-497.

Koplin, J.R. 1973. Differential habitat use by sexes of American Kestrels wintering in northern California. Raptor Res. 7 : 39-42.

Laughlin, S.B., and D.P. Kibbe. 1985. The Atlas of Breeding Birds of Vermont. University Press of New England, Hanover, New Hampshire.

Marquiss, M. 1980. Habitat and diet of male and female Hen Harriers in scotland in winter. Br. Birds 73: 555-560.

Marquiss, M., and I. Newton. 1981. A radio-tracking study of the ranging behaviour and dispersion of European sparrowhawks Accipiter nisus. J. Anim. Ecol. 51: 111133.

- 1982. Habitat preference in male and female Sparrowhawks Accipiter nisus. Ibis $124: 324-328$.

Martin, J.W. 1987. Behavior and habitat use of breeding Northern Harriers in southwestern Idaho. Raptor Res. $21: 57-66$.

Mueller-Dombois, D., and H. Ellenberg. 1974. Aims and Methods of Vegetation Ecology. John Wiley and Sons, Inc., New York, New York. 
Neu, C.W., C.R. Byers, and J.M. Peek. 1974. A technique for analysis of utilization-availability data. J. Wildl. Mgmt. 38: 541-545.

Newton, I. 1976. Population limitation in diurnal raptors. Can. Field-Nat. 90: 274-300.

- 1979. Population Ecology of Raptors. Buteo Books, Vermillion, South Dakota.

Newton, I., I. Wyllie, and R. Mearns. 1986. Spacing of Sparrowhawks in relation to food supply. J. Anim. Ecol. 55: 361-370.

Olendorff, R.R., and M.N. Kochert. 1977. Land management for the conservation of birds of prey. Pp. 294-307 in World Conference on Birds of Prey, Report of Proceedings (R.D. Chancellor, ed.). International Council for Bird Preservation, Great Britain.

Olendorff, R.R., R.S. Motroni, and M.W. Call. 1982. Raptor management- The state of the art in 1980. U.S. Dept. of the Interior, Bureau of Land Management. Technical Note 345 .

Peterson, R.T., and M. Mckenney. 1968. A Field Guide to Wildflowers of Northeastern and Northcentral North America. Houghton Mifflin Company, Boston, Massachusetts.

Phelan, F.J.S., and R.J. Robertson. 1978. Predatory responses of a raptor guild to changes in prey density. Can. J. Zool. 56:2565-2572

Picozzi, N. 1978. Dispersion, breeding and prey of the Hen Harrier Circus cyaneus in Glen Dye, Kincardineshire. Ibis 120: 498-509.

- 1980. Food, growth, survival and sex ratio of nestling Hen Harriers circus c. cyaneus in orkney. ornis scand. 11: 1-11.

- 1984. Sex ratio, survival and territorial behaviour of polygynous Hen Harriers Circus c. cyaneus in Orkney. Ibis 126: 356-365.

Ratcliffe, D.A. 1977. Discussion of future action, research and management. Pp. 414-417 in world Conference on Birds of Prey, Report of Proceedings (R.D. Chancellor, ed). International Council for Bird Preservation, Great Britain. 
Robinson, S.K., and R.T. Holmes. 1982. Foraging behavior of forest birds: the relationships among search tactics, diet, and habitat structure. Ecology 63: 1918-1931.

Russell, H.S. 1982. A Long Deep Furrow, Three Centuries of Farming in New England. University Press of New England, Hanover, New Hampshire.

Schipper, W.J.A. 1973. A comparison of prey selection in sympatric harriers, Circus species, in Western Europe. Le Gerfaut 63: 17-120.

- 1977. Hunting in three European harriers (Circus) during the breeding season. Ardea 65: 53-72.

Schipper, W.J.A., L.S. Buurma, and P.H. Bossenbroek. 1975. Comparative study of hunting behavior of wintering Hen Harriers Circus cyaneus and Marsh Harriers Circus aeruginosus. Ardea 63: 1-29.

Sealy, S.G. 1967. Notes on the breeding biology of the Marsh hawk in Alberta and Saskatchewan. Blue Jay 25: 63-69.

Simmons, R.E., and P.C. Smith. 1985. Do Northern harriers (Circus cyaneus) choose nest sites adaptively? Can. J. 2001. 63:494-498.

Simmons, R.E., P. Barnard, R.B. MacWhirter, and G.L. Hansen 1986a. The influence of microtines on polygyny, productivity, age and provisioning of breeding Northern Harriers: a 5-year study. Can. J. Zool. 64: 2447-2456.

Simmons, R.E., P.C. Smith, and R.B. MacWhirter. 1986b. Hierarchies among Northern Harrier (Circus cyaneus) harems and the costs of polygyny. J. Anim. Ecol. 55: 755-771.

Smith, C.F., ED. 1979. Proceedings of the endangered species conference. U.S. Fish and Wildl. Serv., Newton Corner, Massachusetts.

Smith, C.F., and R. Choate, EDS. 1985. Proposed revision of New Hampshire's list of threatened and endangered species, The Audubon Society of New Hampshire. U.S. Fish and Wildl. Serv., Newton Corner, Massachusetts.

Southern, H.N, and V.P. Lowe. 1968. The pattern of distribution of prey and predation in Tawny owl territories. J. Anim. Ecol. 37: 75-97.

Steel, R.G.D., and J.H. Torrie. 1960. Principles and Procedures of Statistics. McGraw-Hill Book Company, Inc., New York, New York. 
Stinson, C.H., D.L. Crawford, and J. Lauthner. 1981. Sex differences in winter habitat of American Kestrels in Georgia. J. Field Ornith. 52: 29-35.

Tate, G.R., and S.M. Melvin. 1987. Population dynamics, habitat use and management needs of the short-eared Owl in Massachusetts, Summary of 1986 Research. Natural Heritage Program, Massachusetts Division of Fisheries and Wildlife, Boston, Massachusetts.

Tate, J.Jr. 1981. The Blue List for 1981. Am. Birds 35: 310 . $227-236$.

1986. The Blue List for 1986. Am. Birds 40:

Tate, J.Jr., and D.J. Tate. 1982. The Blue List for 1982. Am. Birds 36: 126-135.

Temeles, E.J. 1986. Reversed sexual size dimorphism: effect on resource defense and foraging behaviors of nonbreeding Northern Harriers. Auk 103: 70-78.

Terres, J.K. 1980. The Audubon Encyclopedia of North American Birds. Alfred A. Knopf, Inc., New York, New York.

Tiner, R.W., Jr. 1984. Wetlands of the United States: Current status and recent trends. U.S. Dept. of the Interior, Fish and Wildl. Serv. Washington, DC.

Toland, B. 1985. Nest site selection, productivity, and food habits of Northern Harriers in southwest Missouri. Natural Areas Journal 5: 22-27.

U.S. Department of Commerce. 1984. 1982 Census of Agriculture, Vol. l. Geographic Area Series, Part 29, New Hampshire. Washington, DC.

Urner, C.A. 1925. Notes on two ground-nesting birds of prey. Auk 42: 31-4l.

Wakeley, J.S. 1979. Use of hunting methods by Ferruginous Hawks in relation to vegetation density. Raptor Res. 13: $116-119$.

Watson, D. 1977. The Hen Harrier. T.E.A.D. Poyser, Ltd., Berkhamsted, Hertfordshire, England.

Westveld, M., R.I. Ashman, H.I. Daldwin, R.P. Holds, J. Lutz, L. Swain, and M. Standish. 1956. Natural forest vegetation zones of New England. J. For. 54: 332-338. 
White, C.M., and T.L. Thurow. 1985. Reproduction of Ferruginous Hawks exposed to controlled disturbance. Condor 87: 14-22.

Williams, B.H., W.H. Coates, and P.N. Scripture. 1943. Soil Survey: Coos County New Hampshire. U.S. Dept. of Agriculture, Bureau of Plant Industry. Series 1937, No. 5 . 